ARTICLE

https://doi.org/10.1038/s41467-020-20161-9

\title{
Bridgin connects the outer kinetochore to centromeric chromatin
}

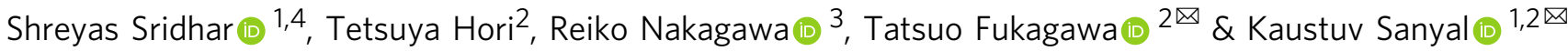

The microtubule-binding outer kinetochore is coupled to centromeric chromatin through CENP-CMif2, CENP-TCnn1, and CENP-UAme1 linker pathways originating from the constitutive centromere associated network (CCAN) of the inner kinetochore. Here, we demonstrate the recurrent loss of most CCAN components, including certain kinetochore linkers during the evolution of the fungal phylum of Basidiomycota. By kinetochore interactome analyses in a model basidiomycete and human pathogen Cryptococcus neoformans, a forkhead-associated domain containing protein "bridgin" was identified as a kinetochore component along with other predicted kinetochore proteins. In vivo and in vitro functional analyses of bridgin reveal its ability to connect the outer kinetochore with centromeric chromatin to ensure accurate chromosome segregation. Unlike established CCAN-based linkers, bridgin is recruited at the outer kinetochore establishing its role as a distinct family of kinetochore proteins. Presence of bridgin homologs in non-fungal lineages suggests an ancient divergent strategy exists to bridge the outer kinetochore with centromeric chromatin.

\footnotetext{
${ }^{1}$ Molecular Mycology Laboratory, Molecular Biology and Genetics Unit, Jawaharlal Nehru Center for Advanced Scientific Research (JNCASR), Bangalore, India 560064. ${ }^{2}$ Laboratory of Chromosome Biology, Graduate School of Frontier Biosciences, Osaka University, Suita, Osaka 565-0871, Japan. ${ }^{3}$ Laboratory for Phyloinformatics, RIKEN Center for Biosystems Dynamics Research (BDR), Kobe, Japan. ${ }^{4}$ Present address: Graduate School of Frontier Biosciences, Osaka University, Suita, Osaka 565-0871, Japan. ${ }^{凶}$ email: tfukagawa@fbs.osaka-u.ac.jp; sanyal@jncasr.ac.in
} 
A ccurate chromosome segregation ensures faithful transmission of the genetic material to progeny. The kinetochore is a multicomplex protein structure assembled on centromere DNA of each eukaryotic chromosome ${ }^{1-4}$ and is attached to the spindle microtubules for accurate chromosome segregation ${ }^{5}$. Components involved in error correction mechanisms, including the spindle assembly checkpoint (SAC), are recruited at kinetochores to ensure the biorientation of sister chromatids in mitosis ${ }^{6-8}$. The inner kinetochore is composed of centromeric histone $\mathrm{H} 3$ variant CENP-ACse4 9-11 and the 16-member constitutive centromere-associated network $(\mathrm{CCAN})^{12-16}$. The outer kinetochore members of the KMN (Knl1, Mis12, and Ndc80 complexes) network ${ }^{1,17}$ are recruited to CCAN to form the kinetochore ensemble across eukaryotes, including budding yeast and vertebrates ${ }^{18}$. Additional components such as the 10-member Dam1 complex (Dam1C) in fungi and the three-member Ska complex in vertebrates localize to the outer kinetochore to ensure accurate kinetochore-microtubule interactions ${ }^{19-24}$.

Genome sequencing data reveal that while the KMN network components are highly conserved ${ }^{25-27}$, the inner kinetochore composition is variable across eukaryotes ${ }^{25-29}$. The $\mathrm{Ndc} 80$ complex (Ndc80C) of the KMN network directly binds to spindle microtubules ${ }^{30-32}$. CCAN proteins, CENP-C $\mathrm{C}^{\mathrm{Mif} 2}$ and CENP$\mathrm{T}^{\mathrm{Cnn} 1}$, have been shown to independently link centromeric chromatin with the KMN network ${ }^{33-38}$. In addition, CENP$\mathrm{U}^{\mathrm{Ame1}}$ functions as a linker in budding yeast ${ }^{39,40}$. CENP-C ${ }^{\mathrm{Mif} 2}$ and CENP-T ${ }^{\mathrm{Cnn} 1}$, through their amino(N)-termini, interact with the KMN network, while their carboxy $(\mathrm{C})$-termini interact with centromeric chromatin ${ }^{41-43}$. CENP-UAmel cooperatively with CENP-C $\mathrm{C}^{\mathrm{Mif} 2}$ also binds to Mis12C, to ensure a linker function in budding yeast ${ }^{39,40}$. These three critical kinetochore linker proteins, CENP-C ${ }^{\text {Mif2 }}$, CENP-T ${ }^{\mathrm{Cnn} 1}$, and CENP-U ${ }^{\text {Ame1, }}$, are often lost or significantly diverged during evolution. Despite the observed loss or functional divergence of linker proteins, the existence of other molecular innovations to bridge centromeric chromatin with the outer kinetochore to ensure accurate chromosome segregation remains largely unknown ${ }^{21,28,44}$. Although each of the kinetochore linker pathways has been shown to play important roles in chromosome segregation, the architectural dependence on a specific pathway varies across species ${ }^{34,35,37}$.

Cryptococcus neoformans is a ubiquitous environmental fungus and an opportunistic pathogen causing fatal cryptococcal meningitis ${ }^{45,46}$. Our previous studies using this model basidiomycete suggested a stepwise kinetochore assembly on a long repetitive regional centromere ${ }^{24,47}$.

In this work, by analyzing a number of fungal genomes, we strikingly find the recurrent absence of most CCAN components, including certain conventional linker proteins, CENP-T ${ }^{\mathrm{Cnn} 1}$ and CENP-UAme1, in the phylum Basidiomycota. We identify "bridgin", a previously undescribed protein, in the kinetochore interactome of $C$. neoformans. We predict the existence of bridgin homologs in eukaryotic lineages outside the fungal kingdom as well. Based on in vivo and in vitro functional analyses, we demonstrate that bridgin connects the outer kinetochore with centromeric chromatin revealing the existence of a distinct strategy to bridge the outer kinetochore and centromeric chromatin across eukaryotes.

\section{Results}

Recurrent independent loss events of CCAN proteins in Basidiomycota. To have a comprehensive understanding of the kinetochore composition in Basidiomycota, we analyzed putative kinetochore homologs using high-confidence protein homology searches combined with secondary and tertiary structure prediction. Species representing 31 fungal orders across the three subphyla, Pucciniomycotina, Ustilagomycotina, and Agaricomycotina, were considered. Additionally, representative species across 7 fungal phyla were included ${ }^{48}$. CENP-A ${ }^{\text {Cse4, the } 16-}$ member CCAN, and the 10-member KMN network were chosen for this study (Fig. 1a and Supplementary Data 1). Our analysis, in accordance with the previous reports $25,26,29$, indicates the robust conservation of CENP-A $\mathrm{A}^{\mathrm{Cse} 4}$ and the $\mathrm{KMN}$ network proteins across basidiomycetes. On the other hand, we observed recurrent loss of most CCAN proteins across 23 of the 31 basidiomycete orders (Fig. 1a). In the subphylum of Agaricomycotina, to which C. neoformans belongs, the loss event may have occurred early at the time of divergence of Wallemiales from other orders. Retention of CCAN proteins in a few discrete orders in the subphyla of Pucciniomycotina and Ustilogamycotina suggests the occurrence of multiple independent loss events of most CCAN subunits (Fig. 1a). The kinetochore linker CENP-C ${ }^{\text {Mif2 }}$ was the only conserved CCAN component across basidiomycetes. Other known linker proteins, CENP-T ${ }^{\mathrm{Cnn} 1}$ and CENP-UAme1, were often lost together. Although the primary protein sequence conservation is low among CENP-T ${ }^{\text {Cnn1 }}$ homologs, they share a typical protein architecture: an N-terminal $\alpha$-helix composed of conserved hydrophobic residues, observed to occur within the PITH domain in Ustilaginales, and the CENP-TCnn1 motif at the $\mathrm{C}$ terminus (Fig. 1b). As a result, the CENP-C ${ }^{\text {Mif2 }}$ pathway remains the only known linker pathway among 23 of the 31 basidiomycete orders investigated. These observations suggest that additional factors may exist to compensate for the recurrent loss of most CCAN proteins in Basidiomycota.

Identification of the kinetochore interactome in C. neoformans. In search of such unknown kinetochore proteins, we attempted to analyze the kinetochore composition in the fungal phylum of Basidiomycota using a relatively well-studied model basidiomycetous yeast $C$. neoformans (Fig. 1a). To comprehensively determine the constitution of the kinetochore and its interactome in vivo, $C$. neoformans strains expressing $3 \times$ FLAG-tagged CENP$\mathrm{C}^{\mathrm{Mif2}}$, Dsn1 (Mis12C), and Spc25 (Ndc80C) under control of the native promoter were generated. The functionality of the $3 \times$ FLAG-tagged proteins was validated by chromatin immunoprecipitation (ChIP) and co-immunoprecipitation (co-IP) assays (Supplementary Fig. 1a-c).

Mass-spectrometry (MS) analyses were performed after FLAGIP for CENP-C ${ }^{\text {Mif2 }}$, Dsn1, and Spc25 from metaphase-enriched (mitotic index $>90 \%$ ) cell population (Fig. 1c and Supplementary Data 2). Nearly all predicted inner kinetochore proteins (CENP$\mathrm{A}^{\mathrm{Cse} 4}$ and CENP-C ${ }^{\mathrm{Mif2}}$ ) and outer kinetochore KMN network components were identified from each of the FLAG-IPs (Table 1 and Supplementary Data 2). Except for CENP-C ${ }^{\mathrm{Mif} 2}$, no components of the CCAN were identified in the IP-MS (Table 1 and Supplementary Table. 2). Identified KMN network components included evolutionarily conserved but previously unannotated ORFs coding for subunits of Mis12C (CNAG_04300 ${ }^{\text {Nsl1 }}$, CNAG_04479Nnfl) and Knl1C (CNAG_03715 ${ }^{\text {Sos7 }}$ ) (Table 1 and Supplementary Data 2). CNAG_03715 ${ }^{\text {Sos7 }}$ (Knl1C) was used as a candidate to authenticate the predicted ORFs as bona fide kinetochore proteins. CNAG_03715 $5^{\text {Sos7 }}$ was bioinformatically identified as the Sos7 homolog in C. neoformans using Schizosaccharomyces pombe Sos $7^{49}$ (Supplementary Fig. 1d, e). Microscopic observations of GFP-CnSos7 suggested a cell-cycledependent kinetochore-exclusive localization in C. neoformans (Fig. 1d and Supplementary Fig. 1f). Further analysis confirmed that while Sos7 was dispensable for cell viability, yet was essential for accurate chromosome segregation in C. neoformans (Supplementary Fig. 1g, h). 
a

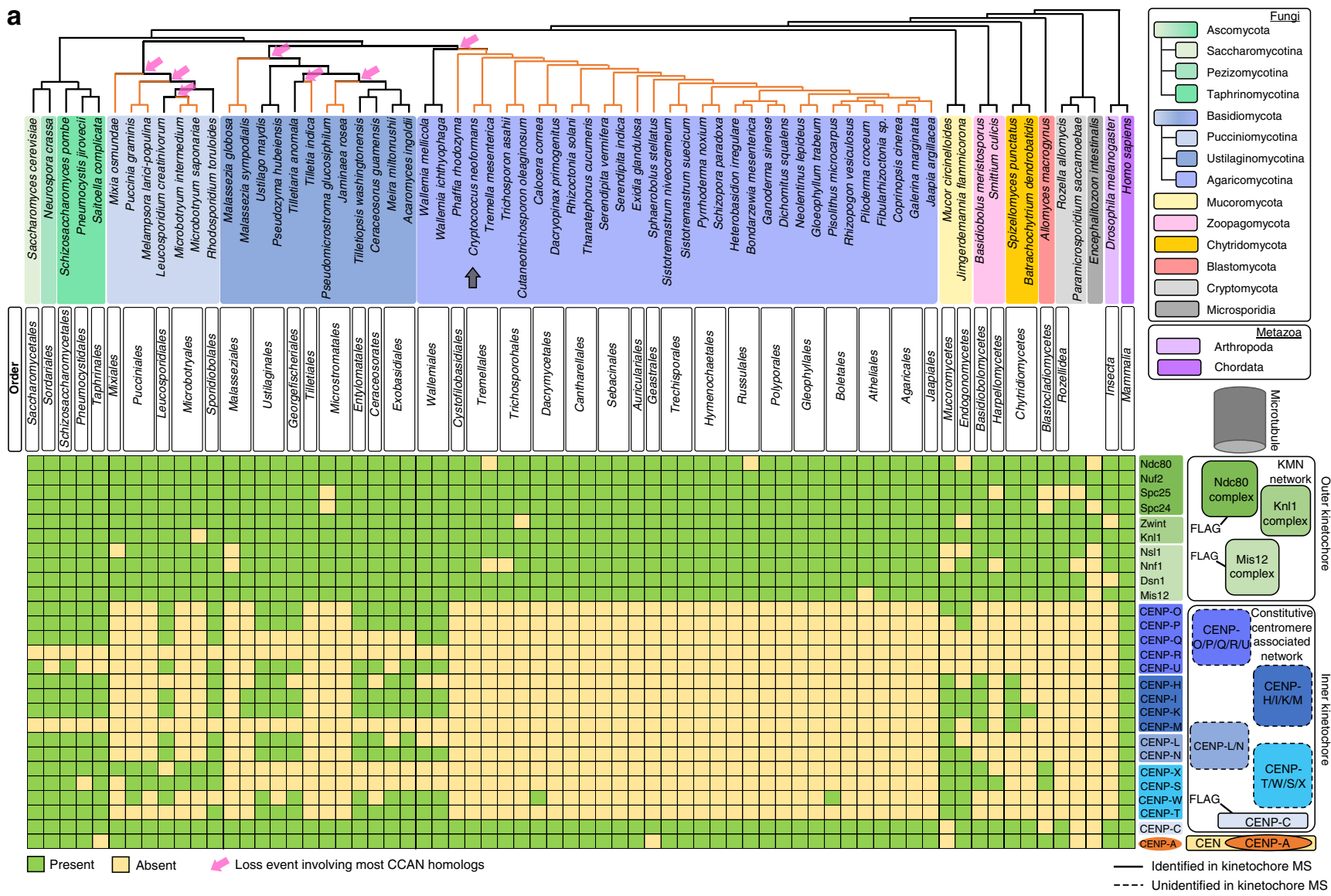

b
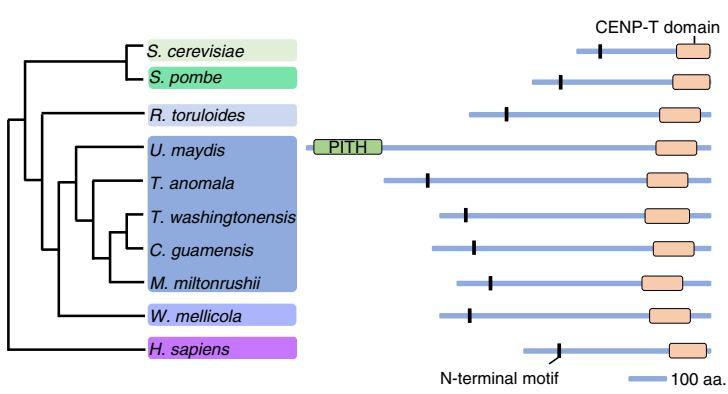

d

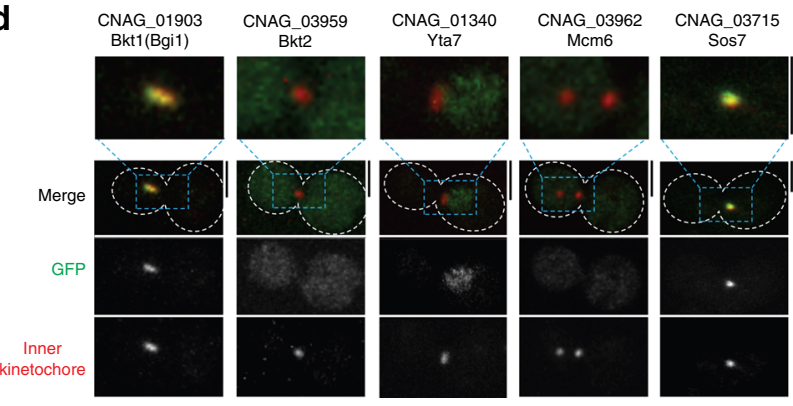

Taken together, the experimental identification of the kinetochore interactome confirms our bioinformatics prediction that C. neoformans retains a single known kinetochore linker pathway through CENP-C ${ }^{\text {Mif2 }}$.

Bridgin (Bgi1) is a basidiomycete kinetochore protein. Next, we attempted to find the existence of unknown kinetochore proteins compensating for the loss of CCAN subunits in Basidiomycota.
C

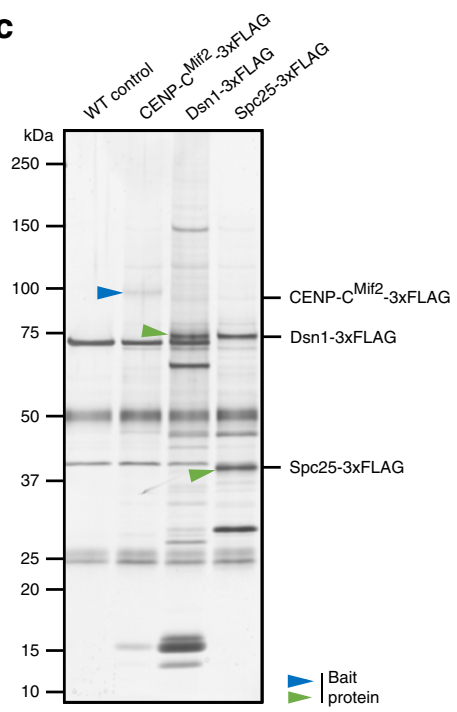

We gained confidence by identifying nearly all known structural kinetochore components from each FLAG-IP-MS experiment. Thus, we hypothesized that it was possible to identify previously undescribed kinetochore proteins, if any, from the identified common interactors of CENP-C ${ }^{\mathrm{Mif} 2}$, Dsn1, and Spc25 (Supplementary Data 2). Among the identified proteins that fulfill this stringent criterion, we categorized two sets of proteins: (a) conserved among basidiomycetes with unknown function and 
Fig. 1 Identification of the kinetochore interactome in Cryptococcus neoformans. a Conservation of kinetochore proteins across the mentioned species. The cladogram represents the relationship between the species; each subphylum is color-coded. The presence (green boxes) or absence (yellow boxes) of each kinetochore protein in every species is shown. Pink arrows indicate loss events of CCAN proteins, excluding CENP-CMif2. Orange lines in the cladogram refer to basidiomycete lineages that have lost most CCAN components. The gray arrow points to C. neoformans. Right, schematic of a typical kinetochore ensemble. FLAG-labeled proteins of kinetochore subcomplexes (CENP-C, Mis12C, and Ndc80C) in C. neoformans are indicted and used for the immunoprecipitation (IP)-mass-spectrometry (MS) identification of the kinetochore interactome. Protein complexes identified (solid borders) or those that remained unidentified (dotted borders) by the IP-MS experiment in C. neoformans are shown. b Domain architectures of identified CENP-TCnn1 homologs among basidiomycetes. Color coding of subphyla is followed as in a. c Proteins eluted after FLAG-IP, of CENP-CMif2 in the C. neoformans strain SHR896 (CENP-C::CENP-CMIF2-3×FLAG), Dsn1 in SHR824 (DSN1::DSN1-3×FLAG), Spc25 in SHR823 (SPC25::SPC25-3×FLAG), and an untagged wild-type (WT) control (H99) after thiabendazole (TBZ) treatment, were separated on a gradient PAGE gel and silver-stained. Blue and green arrows mark the inner and outer kinetochore bait proteins, respectively. $\mathbf{d}$ Micrographs of $C$. neoformans cells at the M phase expressing GFP-tagged proteins identified by the IP-MS screen. Kinetochores are marked by inner kinetochore proteins, CENP-CMif2 -mCherry for Bgi1 ${ }^{\text {Bkt1 }}$ in SHR876 (BG11::BGl1-V5-GFP), Bkt2 in SHR897 (BKT2::BKT2-V5GFP), and Yta7 in SHR842 (YTA7::YTA7-V5-GFP) or mCherry-CENP-ACse4 for Mcm6 in SHR905 (MCM6::MCM6-V5-GFP) and Sos7 in SHR845 (SOS7:: GAL7p-GFP-SOS7). Scale bar, $3 \mu \mathrm{m}$. Source data are available as a Source Data file.

Table 1 List of kinetochore proteins obtained in the kinetochore IP-MS.

\begin{tabular}{|c|c|c|c|c|c|c|c|c|c|}
\hline Complex & Protein & C (\%) & TSC & C (\%) & TSC & C (\%) & TSC & C (\%) & TSC \\
\hline \multirow{3}{*}{$\mathrm{Ndc} 80$} & Nuf2 & 2.7 & 1 & 10 & 4 & 44 & 67 & 69 & 683 \\
\hline & Spc25 & 19 & 7 & 21 & 6 & 64 & 90 & 84 & 581 \\
\hline & Spc24 & - & - & 23 & 6 & 73 & 51 & 82 & 313 \\
\hline \multirow[t]{4}{*}{ Mis12 } & Nsl1 (CNAG_04300) & - & - & 15 & 10 & 67 & 84 & 47 & 24 \\
\hline & Nnf1 (CNAG_04479) & - & - & 12 & 6 & 52 & 222 & 39 & 68 \\
\hline & Dsn1 & - & - & 26 & 20 & 61 & 607 & 48 & 127 \\
\hline & Mis12 $12^{\mathrm{Mtw} 1}$ & - & - & 30 & 11 & 72 & 287 & 49 & 56 \\
\hline CCAN & CENP-CMif2 & - & - & 48 & 272 & 35 & 66 & - & - \\
\hline CENP-A & CENP-ACse 4 & - & - & 24 & 9 & 20 & 10 & 6 & 2 \\
\hline
\end{tabular}

termed them basidiomycete kinetochore proteins (Bkts), which included CNAG_01903 ${ }^{\text {Bkt1 }}$, CNAG_03959 ${ }^{\text {Bkt2 }}$, and CNAG_02701 ${ }^{\text {Bkt3 }}$ (Supplementary Fig. 1i), and (b) known chromatin-interacting proteins with uncharacterized kinetochore function, that included CNAG_01340 ${ }^{\mathrm{Yta} 7}$ and all components of the evolutionarily conserved DNA replication initiation factors Mcm2-7 of the MCM complex ${ }^{50}$ (Supplementary Fig. 1j). We characterized CNAG_03962 ${ }^{\mathrm{Mcm} 6}$ as the representative test candidate for the MCM complex. As a secondary screen, each of these five candidates was expressed as C-terminally V5-GFP epitope-tagged proteins from their endogenous locus. We could observe subcellular localization in strains expressing CNAG_01903 Bkt1, CNAG_03959Bkt2, CNAG_01340 ${ }^{\text {Yta7 }}$, or CNAG_03962 ${ }^{\mathrm{Mcm} 6}$. The protein encoded by CNAG_01903 ${ }^{\text {Bkt1 }}$ colocalized at the kinetochore with CENP-C ${ }^{\text {Mif2 }}$ (Fig. 1d and Supplementary Fig. 1k). Other proteins did not show exclusive kinetochore localization, although some puncta of CNAG_01340 ${ }^{\mathrm{Yta} 7}$ and CNAG_03962 ${ }^{\mathrm{Mcm} 6}$ colocalized transiently with inner kinetochore proteins (CENP-C ${ }^{\mathrm{Mif} 2}$ or CENP-A ${ }^{\mathrm{Cse} 4}$ ) at G1/S stage (Supplementary Fig. 1k). Recently, Yta7 was shown to act as a deposition factor for CENP-A ${ }^{\text {Cse } 4} 51$. Based on the localization dynamics of Bkts, CNAG_01903 ${ }^{\text {Bktl }}$ was taken forward as a bona fide candidate kinetochore protein due to its exclusive kinetochore localization. Considering its identified function through this study, we refer to Bkt1 as "bridgin" (Bgi1) henceforth.

Multiple outer kinetochore receptors recruit bridgin. Crosslinked ChIP analysis suggested that bridgin localized to the centromere at $\mathrm{M}$ phase but absent at $\mathrm{S}$ phase (Fig. 2a and Supplementary Fig. 2a). We validated the localization by microscopic observations (Supplementary Fig. 1k). Cellular pools of bridgin were relatively uniform through the cell cycle, suggesting that the $\mathrm{G} 2 / \mathrm{M}$ kinetochore localization of bridgin is not due to a higher level of protein expression at the corresponding stage (Supplementary Fig. 2b). Further, bridgin localization at the kinetochore was not affected by the treatment of a microtubuledepolymerizing drug, thiabendazole (TBZ) (Supplementary Fig. 2c), suggesting that loss of spindle integrity did not influence the kinetochore localization of bridgin.

Our previous study suggested a stepwise assembly of the kinetochore in $C$. neoformans, yet no sequential assembly of kinetochore subcomplexes was established ${ }^{24}$. We investigated where bridgin localizes within the kinetochore localization hierarchy. We adopted a microscopy-based kinetochore interdependency assay strategy involving a test kinetochore protein in the background of a conditional kinetochore mutant ${ }^{52}$ (Fig. 2b). Conditional mutants of

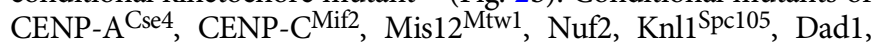
and Dad2 in C. neoformans were generated by driving expression of each of these GFP/mCherry-tagged kinetochore proteins under the control of the GAL7 promoter $(G A L 7 p)$. Upon reduced protein levels due to nonpermissive conditions of the GAL7p-driven expression (Supplementary Fig. 2d, e), the kinetochore mutants displayed a lack of growth (Supplementary Fig. 2f) on account of reduced cell viability (Supplementary Fig. $2 \mathrm{~g}$ ). These results, in accordance with our previous report ${ }^{53}$, validated the effective repression mediated by GAL7p. Using this experimental strategy, we determined that Mis12C and $\mathrm{Ndc} 80 \mathrm{C}$ influence the stability of each other at the kinetochore (Supplementary Fig. 3a, b). Knl1C (Supplementary Fig. 3c-f) and Dam1C (Supplementary Fig. 3g-i)) independently require the Mis $12 \mathrm{C}-\mathrm{Ndc} 80 \mathrm{C}$ platform to be localized 

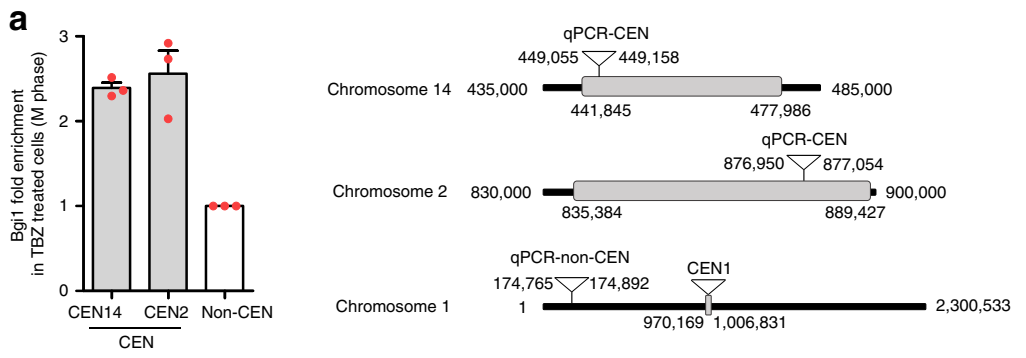

\section{b}

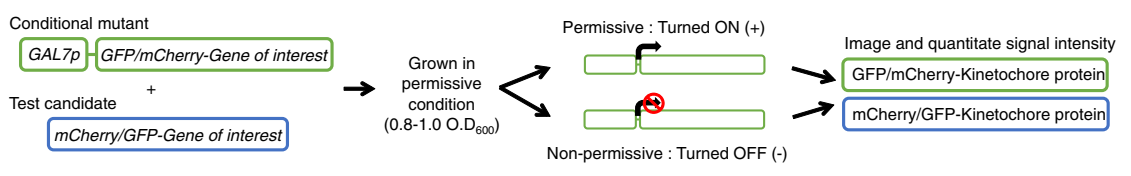

Permissive : $1 \%$ Yeast extract, $2 \%$ Peptone, $2 \%$ Galactose (YPG) Non-Permissive : $1 \%$ Yeast extract, $2 \%$ Peptone, $2 \%$ Dextrose (YPD)
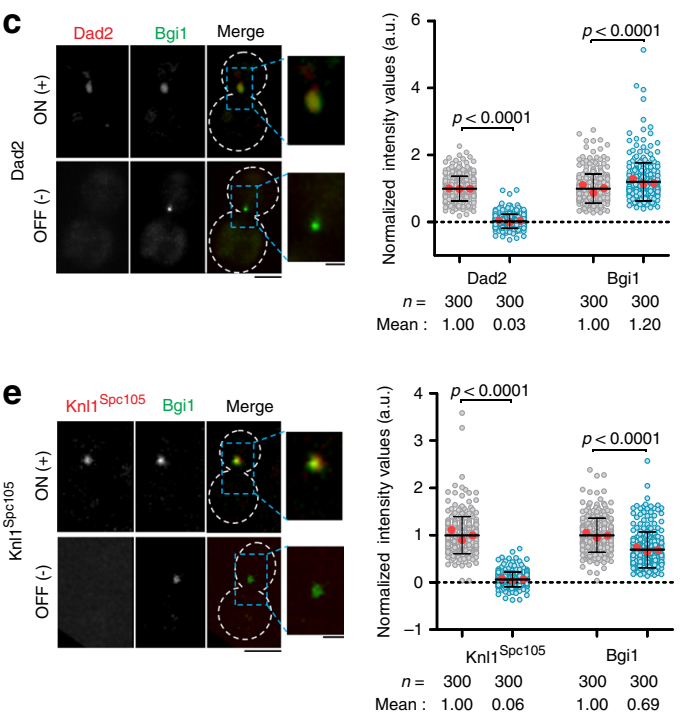
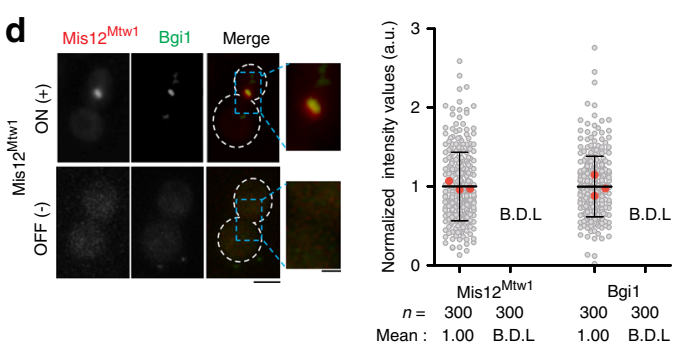

f
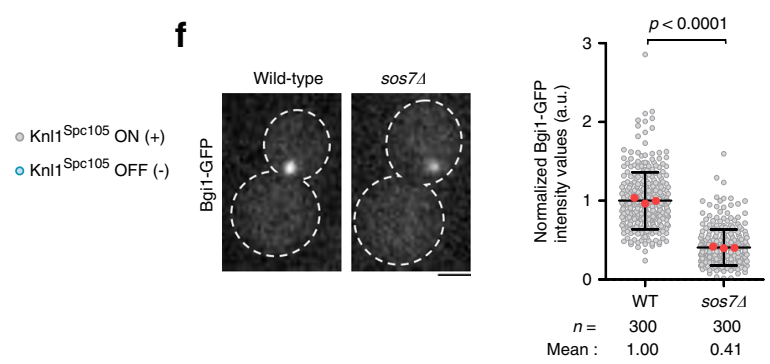

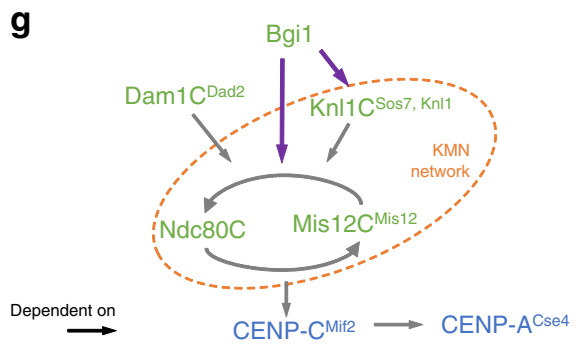

Fig. 2 Bridgin assembles onto the KMN network platform. a Left, enrichment of Bgi1 at M-phase kinetochores in SHR870 (BG/1::BG/1-V5-GFP) cells by cross-linked chromatin immunoprecipitation (ChIP) followed by quantitative polymerase chain reaction ( $q P C R$ ). The data represent the mean \pm standard deviation (S.D.) of three independent experiments. Right, schematic representing the location of qPCR primers used. Centromeric sequences are defined by grey boxes. b Steps followed to determine localization interdependency at the kinetochore among its subcomplexes. c-e Left, a representative image of Bgi1-V5-GFP in c SHR906 (DAD2::GAL7p-mCherry-DAD2), d SHR907 (MIS12MTW1::GAL7p-mCherry-MIS12MTW1) and e SHR945 (KNL1SPC105::GAL7p-mCherryKNL1 ${ }^{S P C 105}$ ) in permissive $(+)$ or nonpermissive $(-)$ conditions of the GAL7p. Scale bar, $3 \mu \mathrm{m} ; 1 \mu \mathrm{m}$ for magnified inset. Right, Bgi1-V5-GFP signals and c mCherry-Dad2, d mCherry-Mis12Mtw1, or e mCherry-Kn11Spc105 in cells with or without Dad2, Mis12Mtw1, or Knl15pc105 expression, respectively, were quantified and normalized to their respective mean signals in the permissive condition of the GAL7p. Signals were measured after 18, 12, and $18 \mathrm{~h}$ in nonpermissive conditions for Dad2, Mis12 ${ }^{\mathrm{Mtw1}}$, and Knl15pc105, respectively. For $\mathbf{d}$, the strong influence of Mis12 ${ }^{\mathrm{Mtw} 1}$ on kinetochore localization of bridgin resulted in signals that were below detectable levels (B.D.L.). For e, bridgin signals in 24 out of 300 cells were below detectable levels. $\mathbf{f} L$ Left, representative images of Bgi1-V5-GFP in wild-type H99 (SOS7) or in sos7 null mutant SHR908 (SOS7::sos74) cells. Scale bar, $2 \mu \mathrm{m}$. Right, Bgi1-V5-GFP signal intensities were quantified and normalized to the mean wild-type signal. c-f The results of three independent experiments with 100 cells each are represented. The red dot represents the mean of one experiment; mean \pm S.D. is shown. For statistical comparison of differences between the samples, Mann-Whitney twotailed analysis was applied, $p$ values show significant differences. $\mathbf{g}$ Schematic describes the observed localization interdependency of inner (blue) and outer (green) kinetochore protein complexes at the C. neoformans kinetochore. Purple arrows highlight the dependency of bridgin on the KMN network. Source data are available as a Source Data file. 
a

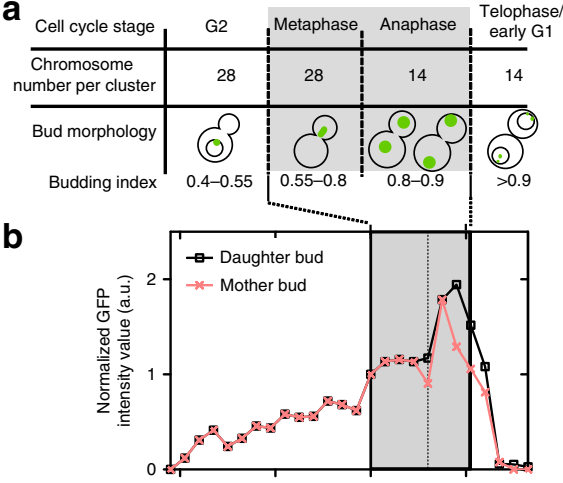

c

d
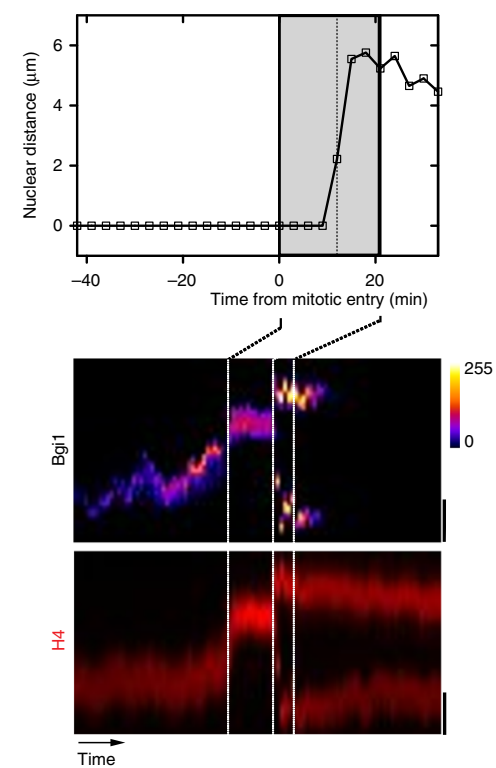

e

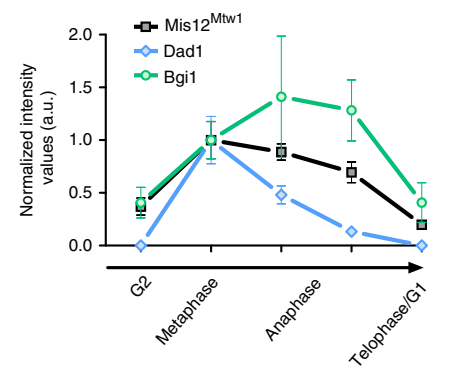

f

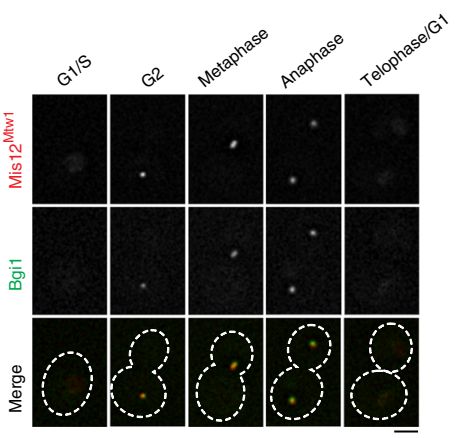

at the kinetochore. Moreover, the $\mathrm{Ndc} 80 \mathrm{C}-\mathrm{Mis} 12 \mathrm{C}$ platform requires the inner kinetochore protein $\mathrm{CENP}-\mathrm{C}^{\mathrm{Mif2}}$ for its kinetochore localization (Supplementary Fig. 3j). Observed interdependencies are summarized in Supplementary Fig. 3k.

Subsequent interdependency analyses with bridgin suggested that its localization to the kinetochore was independent of the
Fig. 3 Bridgin reaches its peak concentration at the kinetochore during anaphase. a Expected chromosome number per kinetochore cluster in the haploid-type strain H99/KN99 and spatial location of bridgin (green) with the corresponding budding index is tabulated. b Signal intensity measurements of Bgi1 in a single cell of the strain SHR843 (BG/1::BG11-V5GFP, H4::H4-mCherry), at an interval of 3 min were measured and normalized to the Bgi1 signal intensity at time point 0 (M-phase entry). c The nuclear marker histone H4 in SHR843 was utilized to measure internuclear distance. A cell is considered to have exited anaphase when nuclear distances have reached their maxima. d Kymograph of the cell used for signal measurements in $\mathbf{b}$. Time interval represented $1 \mathrm{~min}$ for a total of $100 \mathrm{~min}$. Scale bar, $2 \mu \mathrm{m}$. e Comparison of the protein levels of Bgi1 in SHR843, and representative outer kinetochore proteins, Mis12 ${ }^{\mathrm{Mtw} 1}$ in

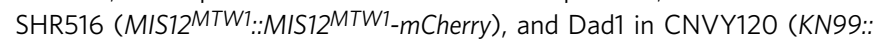
H3p-GFP-DAD1). Signal intensities of each kinetochore protein were quantified and normalized to the mean of their metaphase signals. The results represent the mean \pm S.D. of five cells. $\mathbf{f}$ Co-localization of Bgi1 and Mis12 ${ }^{\mathrm{Mtw1}}$ in SHR869 (BG11::BGI1-V5-GFP, MIS12 ${ }^{\text {MTW1::MIS12 }}{ }^{\text {MTW1-mCherry) }}$ at various stages of the cell cycle in an asynchronous culture. Scale bar, $3 \mu \mathrm{m}$. Source data are available as a Source Data file.

Dam1C subunit Dad2 (Fig. 2c). On the other hand, bridgin's kinetochore localization was entirely compromised in the Mis12 ${ }^{\mathrm{Mtwl}}$ (Mis12C) conditional mutant (Fig. 2d). Considering that Mis12C and $\mathrm{Ndc} 80 \mathrm{C}$ require each other for their kinetochore stability (Supplementary Fig. 3a, b), it would be difficult to distinguish their individual contributions to bridgin localization using the interdependency assay. Further, we suspect that bridgin's kinetochore localization would also be affected in $\mathrm{Ndc} 80 \mathrm{C}$ conditional mutants. Downstream of the Mis12C-Ndc80C platform, the role of Knl1C components, Knl1 ${ }^{\text {Spc105 }}$ and Sos7, on bridgin's localization at the kinetochore, was tested. Bridgin levels at the kinetochore were reduced to $69 \%$ and $41 \%$ as compared to the wild type in the conditional mutant of Knl1 $\mathrm{Spc105}$ and the null mutant of sos7, respectively. Thus, both Knl1C components partially contributed to bridgin's kinetochore recruitment (Fig. 2e, f). Taken together, we demonstrate that the recruitment of bridgin at the kinetochore occurs downstream of KnllC and Mis12C-Ndc80C, suggesting that bridgin has multiple binding sites within the KMN network (Fig. 2g).

Bridgin levels at the kinetochore peak at anaphase. To understand how bridgin dynamics is regulated during cell-cycle progression, we analyzed its signal intensities at the kinetochore. Bridgin localized to the kinetochore starting from G2 until telophase/G1 (Fig. 3a-d and Supplementary Fig. 1k). The signal intensities of bridgin at the kinetochore reached the peak immediately post-anaphase onset, attaining an average of $\sim 150 \%$ of metaphase (Fig. 3b, d, e). The dynamic intensities of other transiently localized kinetochore proteins Mis12 $2^{\mathrm{Mtwl}}$ (KMN network) and Dad1 (Dam1C) were measured. Mis12 ${ }^{\mathrm{Mtw} 1}$ localized to the kinetochore during G2 and persisted until telophase/ G1, reaching the maximum signal intensity during metaphase (Fig. 3e). Dad1 (Dam1C) localized at the kinetochore exclusively postmitotic onset, reaching peak intensities at metaphase and reducing sharply to an almost undetectable level in late anaphase (Fig. 3e). Analysis of bridgin and Mis12 $2^{\mathrm{Mtw} 1}$ localization in an asynchronous population further validated their co-localization to the kinetochore from G2 to telophase/G1 (Fig. 3f). Having observed bridgin's enrichment at the kinetochore, its dependence on the outer kinetochore KMN proteins, kinetochore localization dynamics, and spindle-independent kinetochore recruitment, we conclude that bridgin, as an outer kinetochore protein, is closely associated with the KMN platform. 

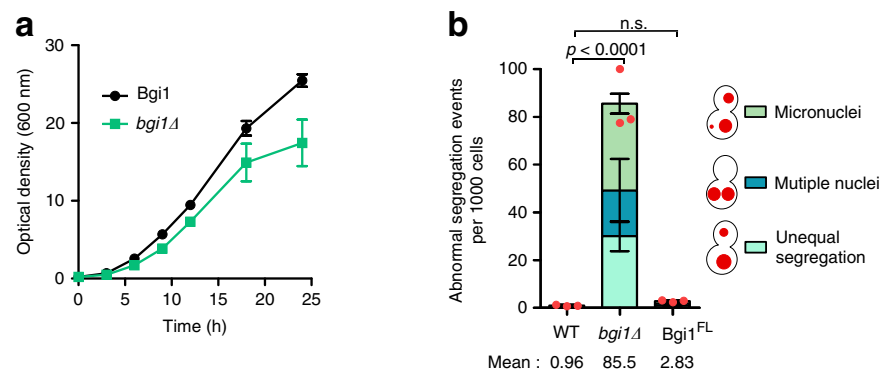

d

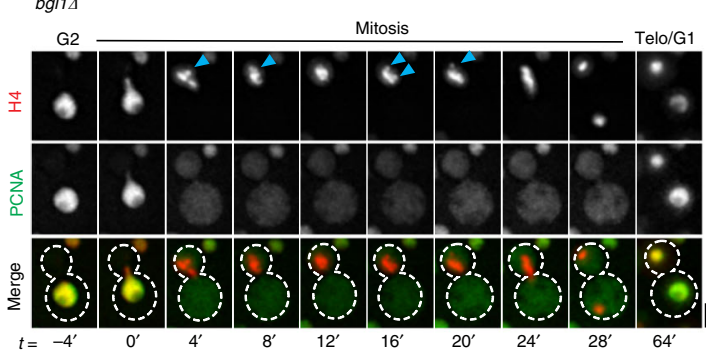

f

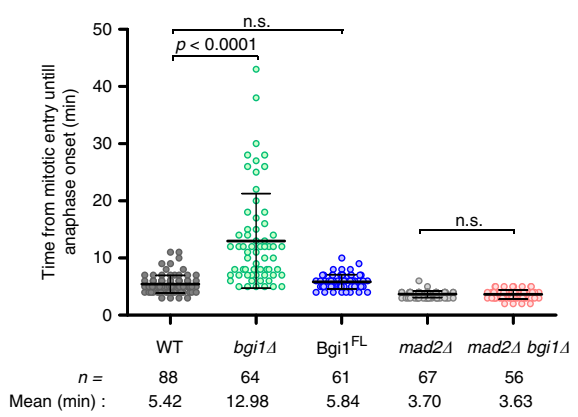

C

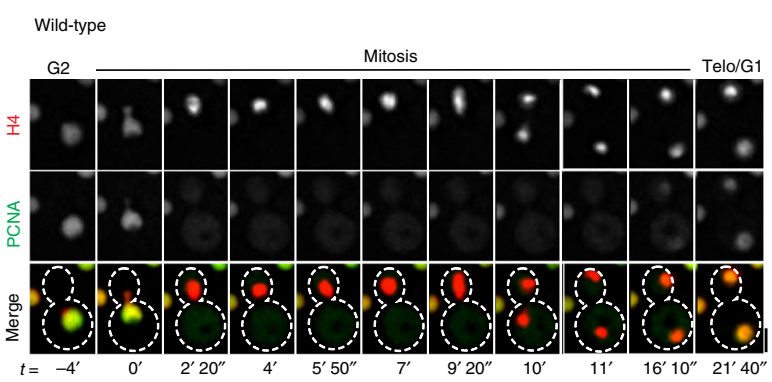

e

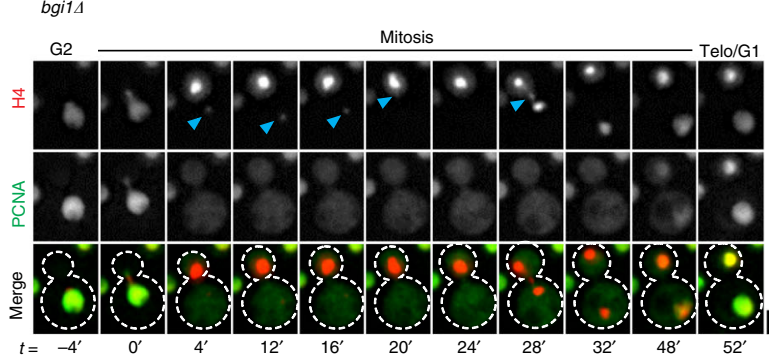

g

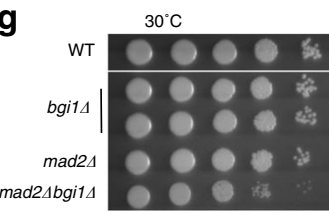

$14^{\circ} \mathrm{C}$

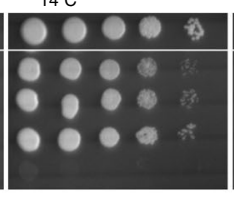

$37^{\circ} \mathrm{C}$

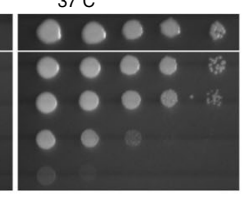

$4 \mu \mathrm{g} / \mathrm{ml}$ TBZ

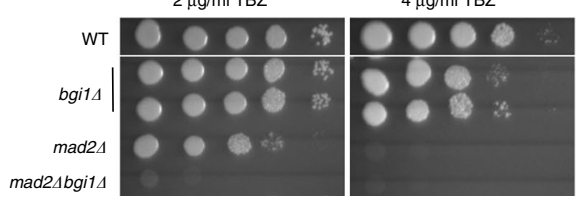

Fig. 4 Loss of bridgin function results in an increased rate of chromosome missegregation and impaired mitotic progression. a Growth curve of wildtype $\mathrm{H} 99$ and bridgin-null mutant strain SHR867 (bgi14::NEO) at $30^{\circ} \mathrm{C} . \mathrm{N}=3$. b The rate of abnormal nuclear segregation events was measured at $30{ }^{\circ} \mathrm{C}$ using histone H4-mCherry in control CNVY121 (BG/1), bridgin-null mutant SHR832 (bgi14::HygB), and the Bgif FL-complimented SHR879 (SHR832::3×FLAG$G F P-B G / F L$ ) strains. The data represent the mean \pm S.D. of three independent experiments. A red dot represents the net abnormal nuclear segregation events per $10^{3}$ cells of one experiment. One-way ANOVA test followed by Dunn's multiple comparison test was used to calculate the statistical significance of differences between the net missegregation events across strains (the $p$ values show the difference compared to wild type, ns nonsignificant). c-e Representative time-lapse images of GFP-PCNA and histone H4-mCherry dynamics in c control strain SHR854 (BG/1) or d, e bridginnull mutant strain SHR873 cells at $30^{\circ} \mathrm{C}$. Time measurements were made from the mitotic onset. Cell-cycle stages were scored for either PCNA localization or chromatin condensation and nuclear migration into the daughter bud. Scale bar, $2 \mu \mathrm{m}$. $\mathbf{d}$ Blue arrows indicate a chromosome that is separated from the compact chromatin mass prior to anaphase onset. e Blue arrows point to a lagging chromosome at the onset of mitosis through anaphase. $\mathbf{f}$ Time from mitotic entry to anaphase onset at $30^{\circ} \mathrm{C}$ was quantified using a nuclear segregation marker, histone $\mathrm{H} 4$, dynamics, and plotted for wild-type control SHR854 (BG/1), bridgin-null mutant SHR873 (bgi14::HygB), the Bgi1 ${ }^{\mathrm{FL}}$ reintegrated strain SHR879, mad2 null mutant SHR741 (mad24: $N E O)$, and the double-mutant strain SHR866 (mad2A::NEO, bgi7 $:: H y g B)$. An internuclear distance of $>1 \mu \mathrm{m}$ was considered as the entry into anaphase. Mean \pm S.D. is indicated. $n$ indicates the number of live cells measured. Each dot represents a single live-cell measurement. Kruskal-Wallis one-way analysis followed by Dunn's multiple comparison test was used to calculate the statistical significance of differences (the $p$ values show the difference compared to their respective controls, wild type or mad24). $\mathbf{g}$ Serial 10 -fold dilutions starting from $2 \times 10^{5}$ cells were spotted for strains wild type (H99),

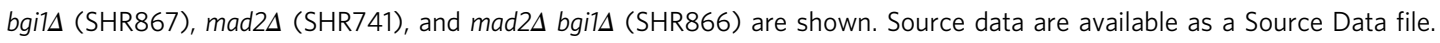

Bridgin is essential for mitotic progression and accurate chromosome segregation. Bridgin-null (bgi1A) strains were generated to further characterize the function of bridgin as a kinetochore protein. bgil $\Delta$ cells exhibited reduced growth rates (Fig. 4a), and $\sim 20 \%$ loss in viability as compared to its wild-type parent strain (Supplementary Fig. 4a). The bgi1s mutant cells also displayed an $\sim 90$-fold increase in the gross missegregation rate, which may account for the reduced viability of bgi $1 \Delta$ (Fig. $4 \mathrm{~b}$ and Supplementary Fig. 4a). These defects of bgils cells were complemented by the reintegration of the full-length bridgin gene, Bgil ${ }^{\mathrm{FL}}$, expressed under the control of its native promoter
(Fig. 4b and Supplementary Fig. 4a). We subsequently examined how bgi1s affected cell-cycle progression. For this, previously described microscopy-based markers such as histone $\mathrm{H} 4$ and PCNA were utilized to determine cell-cycle stages ${ }^{24,53}$. The results were summarized in Supplementary Fig. $4 \mathrm{~b}$. In the wild type, the nucleus migrated into the daughter cell as a coalesced mass at the onset of $M$ phase, followed by its equal segregation in anaphase (Fig. 4c). On the other hand, bgils cells exhibited lagging chromosomes at the $\mathrm{M}$ phase, suggesting inaccurate kinetochore-microtubule attachments (Fig. 4d, e). The live-cell analysis revealed that while wild-type cells spent an average of 18 
a

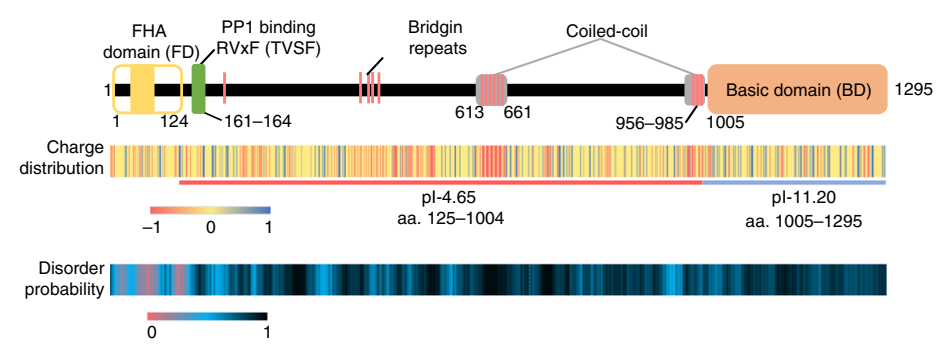

b
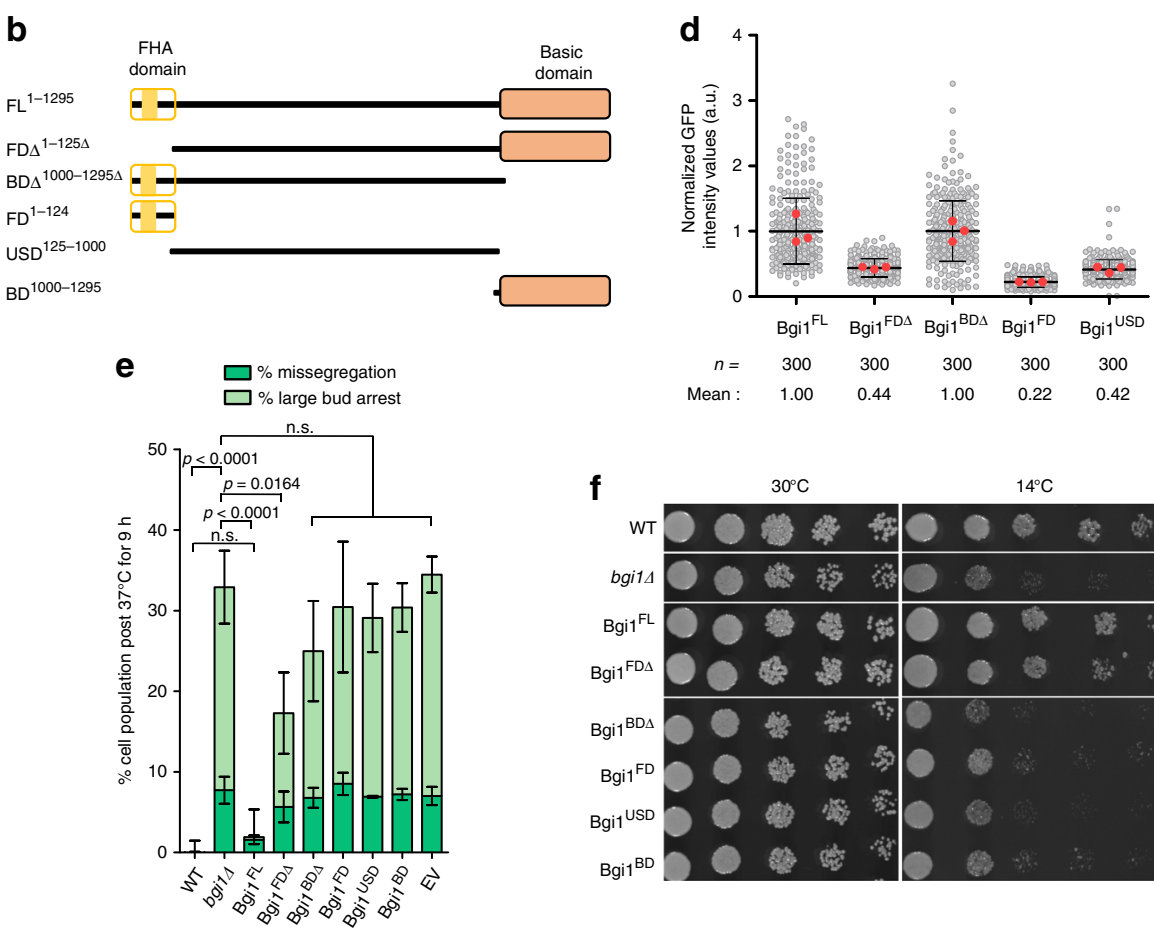

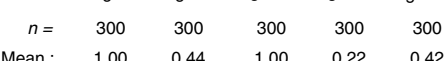

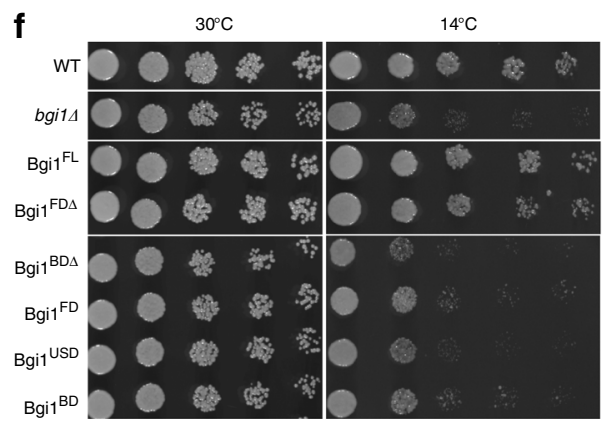

C

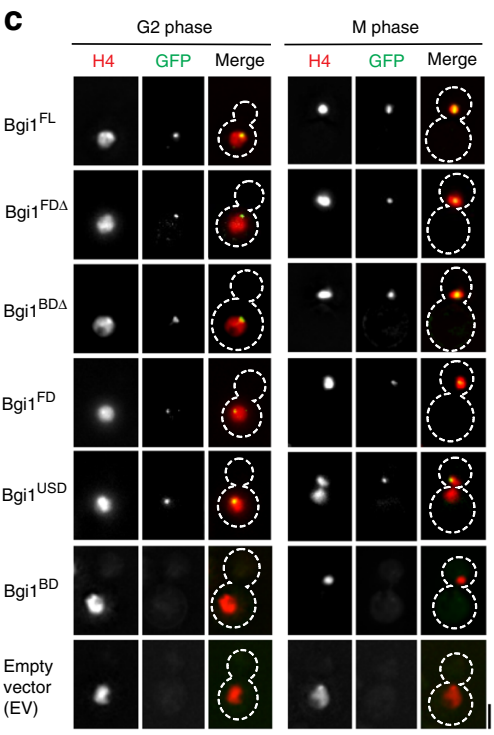

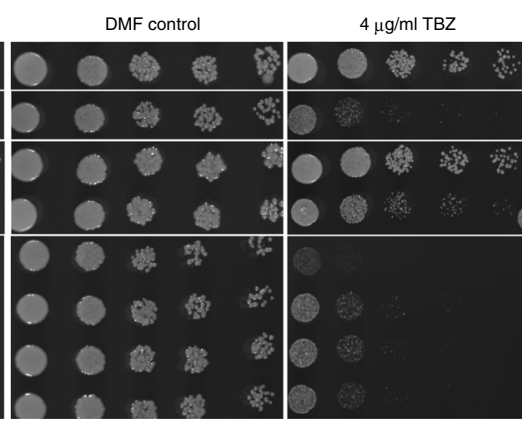

Fig. 5 The basic domain of bridgin is dispensable for its kinetochore recruitment but not for its function. a Schematic describing predicted features of bridgin. Charge distribution of amino acid residues was predicted with a window size of 2 using EMBOSS charge. The disorder probability of bridgin was calculated using IUPRED2A. $\mathbf{b}$ Schematic of domain deletion constructs of bridgin used in this study. Constructs were generated with a $3 \times F L A G-G F P$ tag at

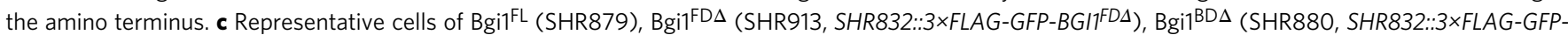

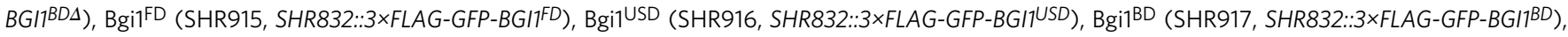
and an empty vector (EV)/FLAG-GFP control (SHR918, SHR832::3×FLAG-GFP) depicting localization of the mentioned GFP constructs in G2 and M phases. Nuclear localization was scored for using the chromatin marker histone H4-mCherry. Scale bar, $3 \mu \mathrm{m}$. d Signal intensities of bridgin constructs mentioned in c were measured at metaphase and normalized to the mean intensity of Bgi ${ }^{\mathrm{FL}}$. The data represent the results of three independent experiments with 100 cells each. The red dot represents the mean of one experiment; mean \pm S.D. is shown. $\mathbf{e}$ The extent of complementation of bridgin constructs mentioned in c, wild-type control CNVY121 (BG/1), and the bridgin-null mutant SHR832 was measured. Cells were grown at $30^{\circ} \mathrm{C}$ until log phase and transferred to $37^{\circ} \mathrm{C}$. Indicated cell populations were measured $9 \mathrm{~h}$ post incubation at $37^{\circ} \mathrm{C}$. All values were normalized to wild-type control levels. Defects in nuclear segregation were measured as mentioned in Fig. 4b. The data represent the mean \pm S.D. of three independent experiments. One-way ANOVA test with Tukey's multiple comparison test was used to calculate the statistical significance of differences between the net missegregation and large-bud arrest populations across strains. $\mathbf{f}$ Cells of varying numbers, $2 \times 10^{4}, 2 \times 10^{3}, 200,100$, and 50 , of strains mentioned in e were spotted on plates as indicated. Dimethylformamide, DMF, solute control. Source data are available as a Source Data file.

min, bgil $\Delta$ cells exhibited a delayed spending $\sim 30 \mathrm{~min}$ in the $\mathrm{M}$ phase. This is an underrepresentation since $\sim 10 \%$ of cells failed to exit the $M$ phase even after $>50$ min (Supplementary Fig. 4c). Within the $M$ phase, the delay occurred before anaphase onset (Fig. 4f and Supplementary Fig. 5f). Further analysis revealed that bgild cells were sensitive to spindle insults (Fig. $4 \mathrm{~g}$ ). Next, we tested whether bgi1 $\Delta$-associated defects are under the surveillance of SAC. mad $2 \Delta$ in the background of bgi1 $\Delta$ alleviated M-phase delay (Fig. 4f and Supplementary Fig. 4d). However, the double mutants (mad2 $\Delta$ bgi1 $\Delta$ ) were conditionally synthetic lethal upon treatment of TBZ $(2 \mu \mathrm{g} / \mathrm{ml})$ or under conditions that compromise the spindle stability (14 and $37^{\circ} \mathrm{C}$ ) (Fig. $4 \mathrm{~g}$ ). Based on nuclear segregation defects, sensitivities to spindle insults, and SACmediated delay in mitotic progression, we conclude that bridgin is important for accurate kinetochore-microtubule interactions required for high-fidelity chromosome segregation. These defects associated with bgild cells activate SAC response to correct for erroneous kinetochore-microtubule attachments.

The basic domain of bridgin is critical for its function. Next, we sought to understand how bridgin, being a part of the kinetochore, contributes to high- fidelity chromosome segregation. Bridgin is predicted to be 1295 -amino acid (aa) long. Its $\mathrm{N}$ terminal region (aa1-124) forms a forkhead-associated (FHA) 
domain (a phosphopeptide recognition domain) followed by an unconventional putative PP1 docking site (aa161-164). In contrast, the remaining region of the protein is predicted to be largely unstructured (Fig. 5a). The C-terminal region (aa1005-1295) that has a pI of 11.20 was termed as the basic domain (BD). The unstructured domain (USD) was defined as the region spanning aa125-1004, which was acidic with a predicted pI of 4.65 (Fig. 5a), and contained 13 repeats of a bridgin consensus motif (Supplementary Fig. 5a and Supplementary Table 1).

Domain deletion constructs of bridgin (Supplementary Fig. 5b and Fig. 5b) wherein the various versions of bridgin are expressed under the control of its native promoter with an $\mathrm{N}$-terminal $3 \times$ FLAG-GFP epitope tag. Each of these constructs was reintegrated into bgils cells expressing histone H4-mCherry to obtain strains expressing truncated bridgin proteins (Fig. 5b). Microscopic estimation of GFP signal intensities of the bridgin constructs suggested that the FHA domain (FD) and USD regions were able to localize independently of each other at the kinetochore, albeit to different extents of $\sim 20 \%$ and $\sim 40 \%$ of the Bgi1 ${ }^{\mathrm{FL}}$ level, respectively (Fig. $5 c$, d). Localization of Bgi1 ${ }^{\mathrm{BD} \Delta}$ at the kinetochore was not significantly different from that of Bgi1 $^{\mathrm{FL}}$ (Fig. 5c, d). Further, a lack of kinetochore localization of Bgil $^{\mathrm{BD}}$ suggested that $\mathrm{BD}$ is dispensable for the kinetochore localization of bridgin. These results suggest that bridgin through its FD and USD makes multiple contacts at the kinetochore, consistent with the observation that bridgin is recruited downstream to multiple outer kinetochore KMN protein subunits (Fig. 2g).

To define the domains necessary for bridgin's function in chromosome segregation, we scored for complementation of the bgild phenotype at $37^{\circ} \mathrm{C}$. This assay condition was used for the ease of scoring due to the enhanced phenotype of M-phase delay (Fig. 5e). In addition, cell growth assays under conditions altering microtubule dynamics (Fig. 5f), and estimation of abnormal segregation defects at $30^{\circ} \mathrm{C}$ was performed (Supplementary Fig. 5c). As expected, Bgil ${ }^{\mathrm{FL}}$ was able to suppress the bgi1 $\Delta$ phenotype significantly (Fig. 5e, f). Partial complementation of phenotype was observed for the mutant expressing Bgi1 ${ }^{\mathrm{FD} \Delta}$. No significant complementation was obtained for any other domain deletion constructs, including the $\mathrm{Bgi1}{ }^{\mathrm{BD}} \Delta$ that localized to the kinetochore similar to Bgi1 ${ }^{\mathrm{FL}}$ levels (Fig. 5e, f). As observed at $37^{\circ} \mathrm{C}$, comparable results were observed for the measured rate of missegregation at $30^{\circ} \mathrm{C}$, albeit weak complementation was observed for Bgil ${ }^{\mathrm{BD}} \Delta$ (Supplementary Fig. $5 \mathrm{c}$ ). Taken together, we conclude that all domains, including $\mathrm{BD}$, which is not involved in kinetochore localization of bridgin, are critical for restoring full bridgin function.

The C-terminal BD of bridgin interacts with chromatin. The impact of bridgin on SAC activity (Supplementary Fig. 5d, e) and spindle dynamics (measured at anaphase, Supplementary Fig. 5f) was tested and found to be unaltered in bgil $\Delta$. Thus, these factors were ruled out as possible reasons for increased missegregation associated with bgi1 $\Delta$ mutants. To address the role of BD toward bridgin function, FLAG-IP for Bgil ${ }^{\mathrm{FL}}$ (using $150 \mathrm{mM} \mathrm{KCl}$ and a more stringent condition of $300 \mathrm{mM} \mathrm{KCl})$ and $\mathrm{Bgi1}{ }^{\mathrm{BD}} \Delta(150 \mathrm{mM}$ $\mathrm{KCl}$ ) was performed and subjected to MS analysis (Fig. 6a and Supplementary Fig. 6a). A comparison of the specific interactors obtained across the Bgi1 ${ }^{\mathrm{FL}}$ and $\mathrm{Bgi1}{ }^{\mathrm{BD}} \Delta$ suggested an enrichment of chromatin-interacting proteins, including inner kinetochore proteins, in Bgil ${ }^{\mathrm{FL}}$ IP as compared to Bgil ${ }^{\mathrm{BD}} \Delta$ IP (Table 2 and Supplementary Data 3). In comparison, outer kinetochore KMN network proteins were identified across the Bgil ${ }^{\mathrm{FL}}$ and $\mathrm{Bgil}{ }^{\mathrm{BD}} \Delta$ IPs (Table 2). Proteins of the KMN network were among the top hits in Bgil ${ }^{\mathrm{BD}} \Delta$ IP (Supplementary Data 3).
Based on the observation that chromatin-interacting proteins were less recovered in $\mathrm{Bgil} \mathrm{BD}^{\mathrm{BD}} \mathrm{IP}$, we hypothesized that $\mathrm{BD}$ might play a role in chromatin interactions. Through co-IP experiments, histone $\mathrm{H} 4$ was found to associate with Bgi1 ${ }^{\mathrm{FL}}$ (150 $\mathrm{mM}$ ) as well as with the inner kinetochore component CENP$\mathrm{C}^{\text {Mif2 }}$ (Supplementary Fig. 6b). On the other hand, histone H4 was greatly reduced in Bgil ${ }^{\mathrm{BD}} \Delta$ IP like the outer kinetochore protein IPs of Dsn1, Spc25, and Spc34 (Dam1C) (Supplementary Fig. 6b). These results raise the possibility that the bridgin-chromatin interaction in vivo occurs directly through $\mathrm{BD}$ and is not a consequence of mere bridgin assembly onto the centromere-localized KMN network platform. We further tested the direct interaction of purified bridgin $\mathrm{BD}$ with free DNA or reconstituted nucleosomes in vitro by electrophoretic mobility shift assay (EMSA). We found that BD was able to bind to DNA (Fig. 6b) and nucleosomes of varying compositions, containing histone H3 or CENP-A (Supplementary Fig. 6c). Taking together, MS results along with in vivo- and in vitro-binding assays strongly indicated that $\mathrm{BD}$ of bridgin interacts with DNA/ chromatin.

Although BD seems to bind DNA nonspecifically in vitro, we cannot rule out the possibility that $\mathrm{BD}$ may exhibit specificity to C. neoformans centromere DNA/chromatin. Alternatively, other factors may restrict BD's centromeric localization in vivo. If the latter possibility is true, overexpression $(\mathrm{OE})$ of bridgin may not alter its localization. The OE assay entailed that chromatinunbound, but nuclear-localized proteins would diffuse into the cytoplasm owing to increased nuclear permeability in the $M$ phase of C. neoformans (Fig. 6c). This is demonstrated by GFPPCNA, a protein with well-established roles in $S$ phase ${ }^{54}$. PCNA is nuclear localized in G2, but being unbound to chromatin in the $\mathrm{M}$ phase, it diffuses into the cytoplasm (see below). OE of GFPBgi1 ${ }^{\mathrm{FL}}$ (Supplementary 6d) resulted in its signals no longer being restricted to the kinetochores (Fig. $6 \mathrm{~d}$ ), rather signals were found to be overlapped with chromatin marked by histone H4 (Fig. 6e). Taking together, we conclude that bridgin interacts with bulk DNA/chromatin nonspecifically in vivo as well.

Further, using the OE strategy (Fig. 6e), we demonstrated that in the absence of $\mathrm{BD}$, signals of $\mathrm{Bgil} \mathrm{B}^{\mathrm{BD} \Delta_{-}} \mathrm{OE}$ were restricted to a punctum, unlike Bgil $\mathrm{FL}_{-} \mathrm{OE}$ localization. Supporting the notion that bridgin localizes to the kinetochore through FD and USD, a single punctum for both overexpressed constructs, Bgil ${ }^{\mathrm{FD}}$ and Bgil USD, was observed. On the other hand, OE of constructs carrying $\mathrm{BD}$ such as Bgil $\mathrm{BD}_{-} \mathrm{OE}$, Bgil ${ }^{\mathrm{FD}} \Delta_{-} \mathrm{OE}$, or $\mathrm{Bgil}^{\mathrm{FL}}-\mathrm{OE}$, resulted in their localization to bulk chromatin. Thus, these observations suggested that BD is necessary and sufficient to bind chromatin in vivo, and the loss of $\mathrm{BD}$ in the $\mathrm{OE}$ constructs was sufficient to restrict bridgin localization to the kinetochore. Taken together, unlike other outer kinetochore proteins, it was surprising that bridgin was able to interact with centromeric chromatin.

Overall net positive charge of the $\mathrm{BD}$ is vital for bridgin function. Toward understanding the significance of bridgin binding to chromatin, we show that loss of bridgin function neither alters the previously described chromatin marks of CpG methylation at $C$. neoformans centromeres ${ }^{47}$ (Supplementary Fig. 6e, f) nor H3K9me2 cellular pools previously shown to be predominantly enriched across centromeres and telomeres ${ }^{55}$ (Supplementary Fig. 6g). To summarize, we observe that BD is dispensable for kinetochore localization of bridgin, but required for its function. However, it remains unclear how BD influences bridgin's function. We hypothesize two possibilities: either BD modulates bridgin function by interacting with specific proteins at chromatin, or BD does so by interacting directly with DNA/ 
a
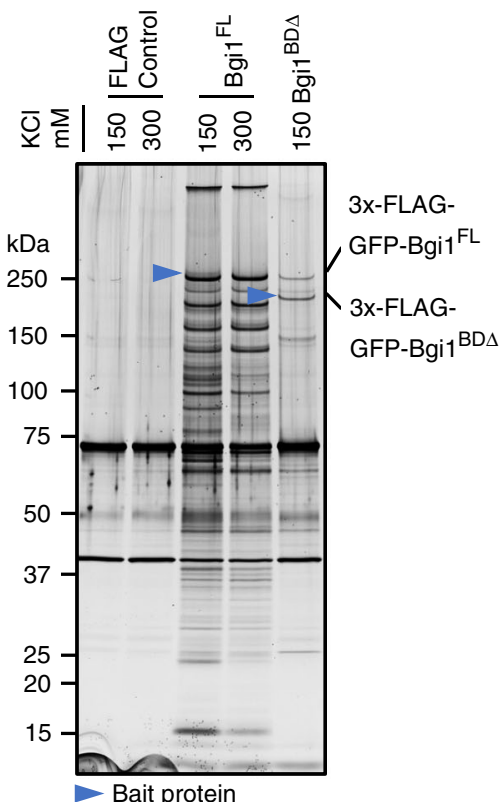

C

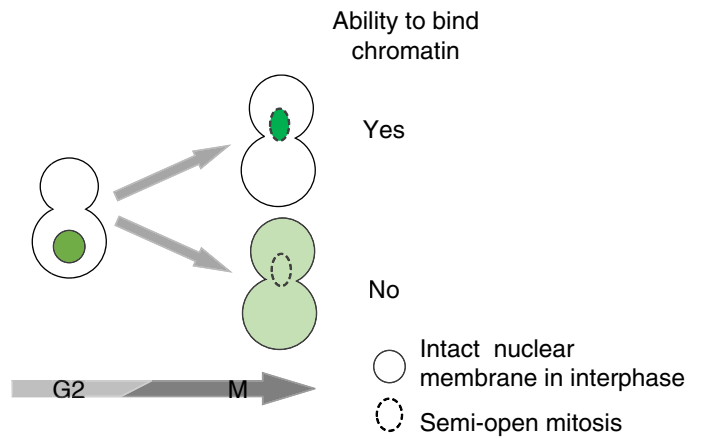

b

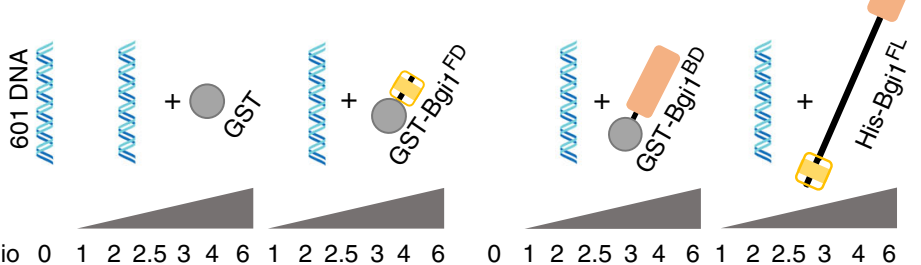

Molar ratio $0 \begin{array}{llllllllllllllllllllllll}1 & 2 & 2.53 & 4 & 6 & 1 & 2 & 2.53 & 4 & 6 & 0 & 122 & 2.53 & 4 & 6 & 1 & 22.53 & 4 & 6\end{array}$

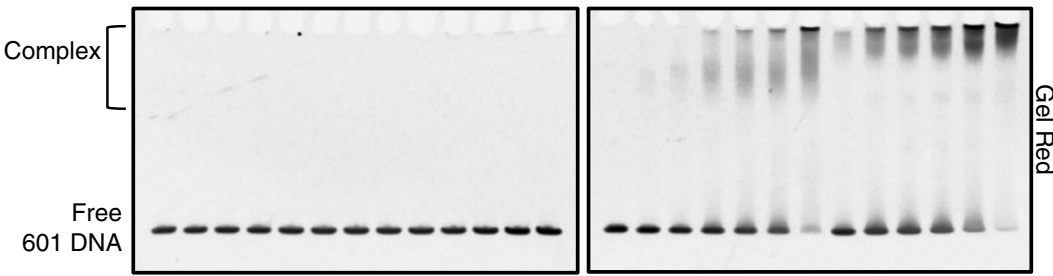

e

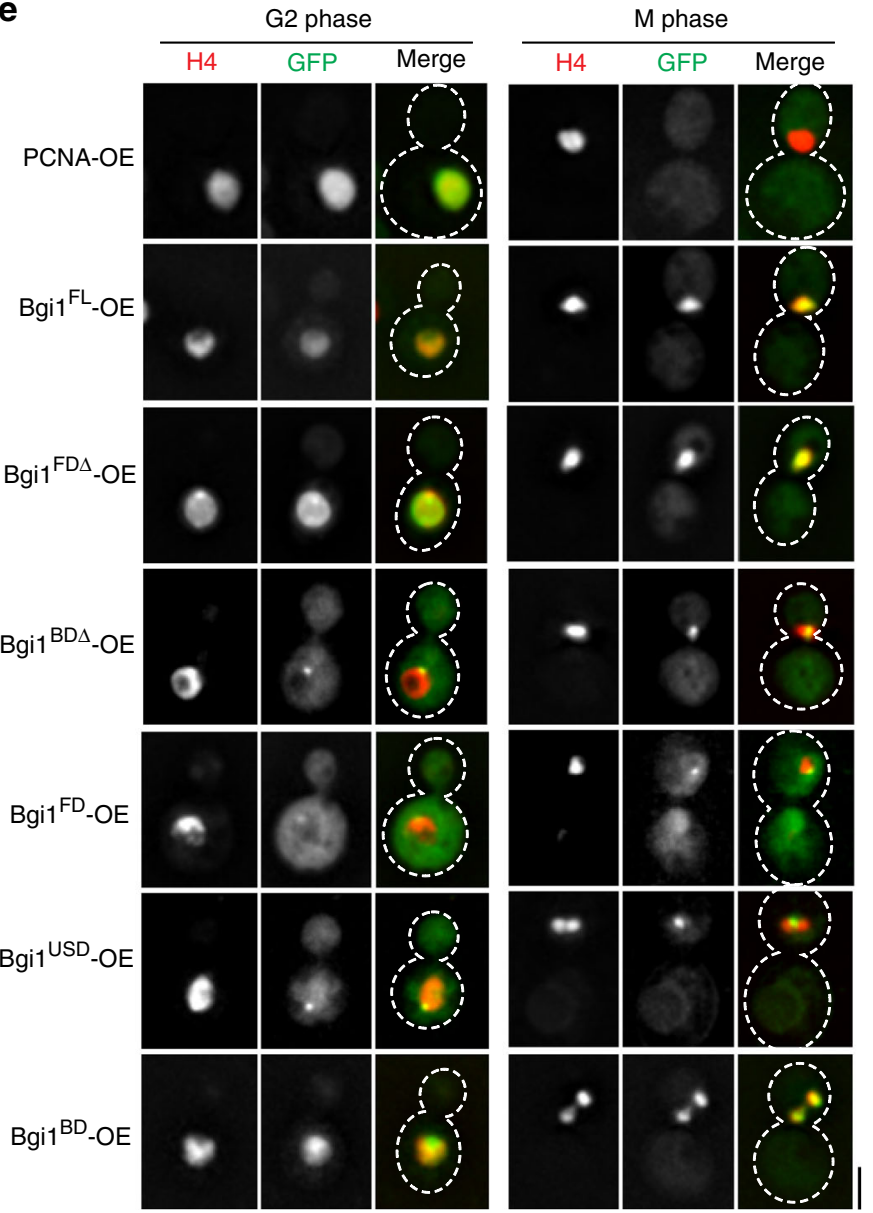

Fig. 6 The basic domain of bridgin has a property to interact with DNA nonspecifically in vitro and in vivo. a Proteins eluted from TBZ-treated cells after FLAG-IP of Bgi $1^{\mathrm{FL}}$ expressing SHR879, Bgi1 $\mathrm{BD} \Delta$ expressing SHR880, and a FLAG control strain SHR942 expressing Bgi1 were separated on a gradient PAGE gel and silver-stained. Blue arrows mark the bait proteins. b Electrophoretic mobility shift assay (EMSA) samples were separated on a PAGE gel and stained with GelRed for visualization. c Chromatin-bound proteins (green) colocalize with the nuclear marker histone H4-mCherry in metaphase, while free nuclear proteins diffuse into the cytoplasm following the entry into mitosis. $\mathbf{d}$ Visualization of GFP-Bgi1 when expressed under the native (SHR847, BG/1:: BG11-V5-GFP) or an overexpression (OE) GAL7 promoter (SHR858, BG11:GAL7p-GFP-BG/1). Outer kinetochore protein Ndc80-mCherry was used to mark the kinetochore. e Visualization of bridgin OE constructs. The expression of OE constructs of Bgi1 ${ }^{\mathrm{FL}}$ (SHR895, SHR832::H3p-GFP-BG17 FL), Bgi1 ${ }^{\mathrm{FD} \Delta}$ (SHR920,

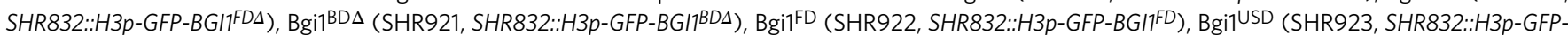
Bgi7 USD) and Bgi ${ }^{B D}$ (SHR924, SHR832::3×FLAG-GFP-BG/1BD), and GFP-PCNA control (SHR854, BGl1, CNVY121::H3p-GFP-PCNA) was visualized in G2 and M phases. Histone H4-mCherry was used to mark chromatin. Scale bar, $3 \mu \mathrm{m}$. Source data are available as a Source Data file. 


\begin{tabular}{|c|c|c|c|c|c|c|c|c|c|c|c|}
\hline \multirow[t]{2}{*}{ Complex/category } & \multirow[t]{2}{*}{ Protein } & \multicolumn{2}{|c|}{$\begin{array}{l}\text { FLAG } \\
\text { control } 150 \mathrm{mM}\end{array}$} & \multicolumn{2}{|c|}{$\begin{array}{l}\text { FLAG } \\
\text { control } 300 \mathrm{mM}\end{array}$} & \multicolumn{2}{|c|}{$\begin{array}{l}\text { Bgi1 FL } 150 \\
\mathrm{mM} \mathrm{KCl}\end{array}$} & \multicolumn{2}{|c|}{$\begin{array}{l}\text { Bgi1 FL } 300 \\
\mathrm{mM} \mathrm{KCl}\end{array}$} & \multicolumn{2}{|c|}{$\begin{array}{l}\text { Bgi1'BD } 150 \\
\mathrm{mM} \mathrm{KCl}\end{array}$} \\
\hline & & C (\%) & TSC & C (\%) & TSC & C (\%) & TSC & C (\%) & TSC & C (\%) & TSC \\
\hline \multicolumn{12}{|c|}{ Chromatin-associated proteins } \\
\hline \multirow{4}{*}{ Histone proteins } & $\mathrm{H} 4$ & 12 & 2 & 51 & 12 & 62 & 139 & 57 & 96 & 51 & 18 \\
\hline & $\mathrm{H} 2 \mathrm{~A} . \mathrm{Z}$ & 6.5 & 1 & 6.5 & 2 & 47 & 13 & 49 & 13 & 6.5 & 2 \\
\hline & $\mathrm{H} 2 \mathrm{~B}$ & - & - & 14 & 2 & 53 & 54 & 44 & 47 & 24 & 4 \\
\hline & $\mathrm{H} 1$ & - & - & - & - & 51 & 18 & 18 & 4 & - & - \\
\hline \multirow[t]{3}{*}{ MCM complex } & Mcm2 & - & - & - & - & 48 & 100 & 37 & 37 & - & - \\
\hline & Mcm3 & - & - & - & - & 56 & 136 & 45 & 56 & - & - \\
\hline & Mcm4 & - & - & - & - & 60 & 119 & 42 & 43 & - & - \\
\hline \multirow{2}{*}{ DNA-binding proteins } & Ku70 & - & - & - & - & 40 & 24 & 44 & 35 & - & - \\
\hline & Ku80 & - & - & - & - & 41 & 34 & 20 & 15 & - & - \\
\hline \multicolumn{12}{|l|}{ Kinetochore proteins } \\
\hline \multirow[t]{4}{*}{$\mathrm{Ndc} 80$} & $\mathrm{Ndc} 80$ & - & - & - & - & 24 & 14 & 17 & 10 & 9.8 & 6 \\
\hline & Nuf2 & - & - & - & - & 30 & 14 & 31 & 12 & 27 & 14 \\
\hline & Spc25 & - & - & - & - & 39 & 15 & 46 & 20 & 18 & 6 \\
\hline & Spc24 & & & & & 39 & 12 & 57 & 20 & 21 & 4 \\
\hline \multirow[t]{2}{*}{ Knl1 } & Sos7 & - & - & - & - & 37 & 12 & 35 & 16 & 2.5 & 1 \\
\hline & Knl1Spc105 & - & - & - & - & 21 & 32 & 13 & 22 & 24 & 34 \\
\hline \multirow[t]{3}{*}{ Mis12 } & Nsl1 & - & - & - & - & 15 & 3 & 30 & 6 & 3.9 & 1 \\
\hline & Nnf1 & - & - & - & - & 25 & 15 & 31 & 17 & 15 & 6 \\
\hline & Dsn1 & - & - & - & - & 34 & 22 & 27 & 19 & 16 & 10 \\
\hline
\end{tabular}

chromatin. To prove further, we performed a domain-swap experiment by replacing bridgin $\mathrm{BD}^{1005-1295}$ with an amino acid stretch of similar properties (length: $300 \mathrm{aa}$, unstructured, nonspecific DNA binding and a $\mathrm{pI}$ of $\sim 10$ ) found in the basic region Ki67-BD 2937-3256 of human Ki67 (Fig. 7a). No evident sequence conservation was observed between the BD of Bgil and the basic region of Ki67 (Supplementary Fig 7a). Ki67 was previously shown to bind nonspecifically to DNA ${ }^{56}$ and functions as a surfactant by coating chromosomes during mitosis ${ }^{57}$. However, Ki67 is not reported to interact with kinetochores ${ }^{58}$. We confirmed that $\mathrm{OE}$ of $\mathrm{Ki} 67^{\mathrm{BD}}$ localized to the entire nucleus, suggesting that it nonspecifically binds to DNA in C. neoformans (Supplementary Fig. 7b). Bgi1 ${ }^{\mathrm{FL}}$, Bgi1 ${ }^{\mathrm{BD} \Delta}$, and $\mathrm{Bgi1}{ }^{\mathrm{BD} \Delta}+\mathrm{Ki} 67^{\mathrm{BD}}$ were expressed under the native bridgin promoter, and each of these versions of Bgil was found to be localized to the kinetochore with comparable intensities when integrated into a bgils background strain (Fig. 7b, c). Weak complementation of bridgin function by Bgil ${ }^{\mathrm{BD}} \Delta$ over bgil $\Delta$ was observed (Fig. $7 \mathrm{~d}$ ). Strikingly however, Bgil ${ }^{\mathrm{BD}} \Delta_{+}+\mathrm{Ki} 67^{\mathrm{BD}}$ was able to complement defects observed in bgild to the extent that was comparable to Bgil ${ }^{\mathrm{FL}}$ (Fig. $7 \mathrm{~d}$ and Supplementary Fig. 7c). These observations were additionally validated by complementation of phenotypes associated with the $\mathrm{Bgil}^{\mathrm{BD} \Delta}$ mutant by the $\mathrm{Bgi1}{ }^{\mathrm{BD}} \Delta+\mathrm{Ki} 67^{\mathrm{BD}}$ chimeric protein in the spotting growth assay (Fig. 7e).

These results strongly indicated that the basic nature of BD contributes to bridgin function through its interaction with chromatin. To provide further evidence, we prepared partial
MNase-digested chromatin (Supplementary Fig. 7d) to perform co-IP of various bridgin and kinetochore protein constructs with histone H4 (Fig. 7f-h). We also examined the enrichment of centromere DNA in these IP samples (Fig. 7h). These results show that Bgil ${ }^{\mathrm{FL}}$, similar to the inner kinetochore linker protein CENP-C ${ }^{\text {Mif2 }}$ but unlike the KMN network component Spc25, interacts with chromatin (Fig. $7 \mathrm{~g}$ ) and enriches at the centromere under these native conditions (Fig. $7 \mathrm{~h}$ ). Bgil ${ }^{\mathrm{BD}} \Delta$, on the other hand, exhibited a reduced interaction with chromatin and did not strongly enrich at the centromeres (Fig. $7 \mathrm{~g}, \mathrm{~h}$ ). Further, Bgil $\mathrm{BD}$ was sufficient to interact with chromatin in vivo, but its binding was not restricted to centromere DNA (Fig. $7 \mathrm{~g}, \mathrm{~h}$ ). Since the $\mathrm{Bgi1}^{\mathrm{BD} \Delta}+\mathrm{Ki} 67^{\mathrm{BD}}$ chimera behaved like Bgil ${ }^{\mathrm{FL}}$, we conclude that the intrinsic basic nature of $\mathrm{BD}$, rather than the specific amino acid sequence, is necessary for bridgin function (Fig. $7 \mathrm{~g}, \mathrm{~h}$ ).

Bridgin maintains physiological levels of outer kinetochore proteins in the $\mathbf{M}$ phase. Having established that bridgin connects the outer kinetochore to centromeric chromatin after being recruited by multiple receptors at the KMN network, we were keen to examine how bridgin contributes to the kinetochore integrity. Fluorescent intensities of inner kinetochore proteins, CENP-A ${ }^{\mathrm{Cse} 4}$ and CENP-C $\mathrm{C}^{\mathrm{Mif} 2}$, and KMN network components of Mis12 ${ }^{\mathrm{Mtw1}}$, Nuf2, and Knl1 ${ }^{\mathrm{Spc105}}$ were analyzed at metaphase and anaphase in wild-type and bgi1 $\Delta$ cells. No significant difference in the levels of inner kinetochore proteins was observed (Supplementary Fig. 7e, f). However, the components of the KMN 
a

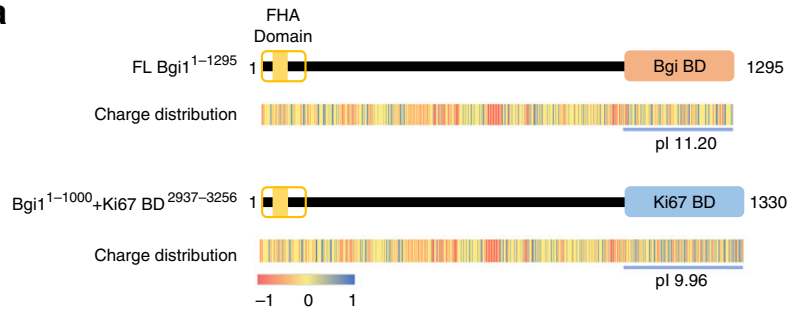

d

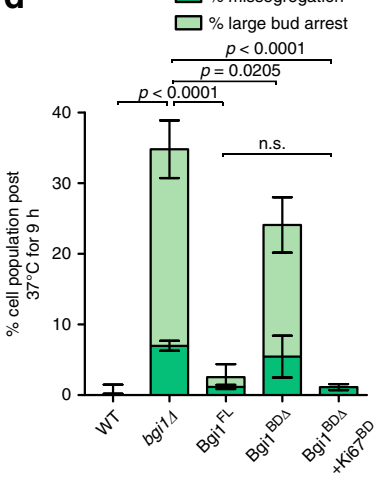

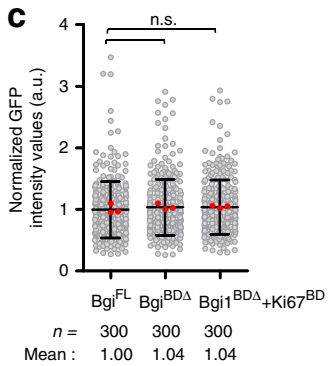

e

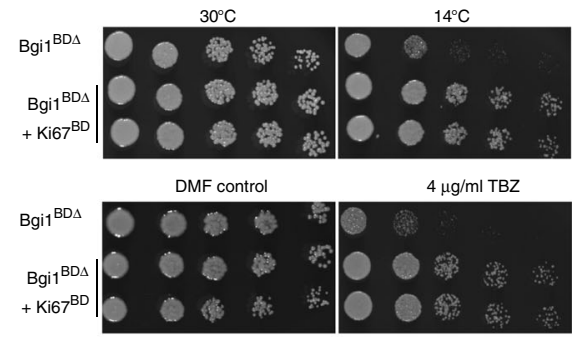

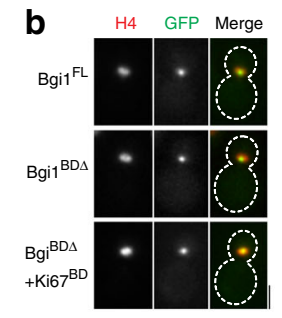

Mean : $\quad 1.00 \quad 1.04 \quad 1.04$ $\mathbf{f}$ M-phase arrested (TBZ 10 $\mu \mathrm{g} / \mathrm{ml})$
cell population

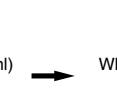
Whole-cell lysate
preparation Partial digestion of
chromatin by MNase
$(<\sim 2 \mathrm{~kb})$

\section{g}
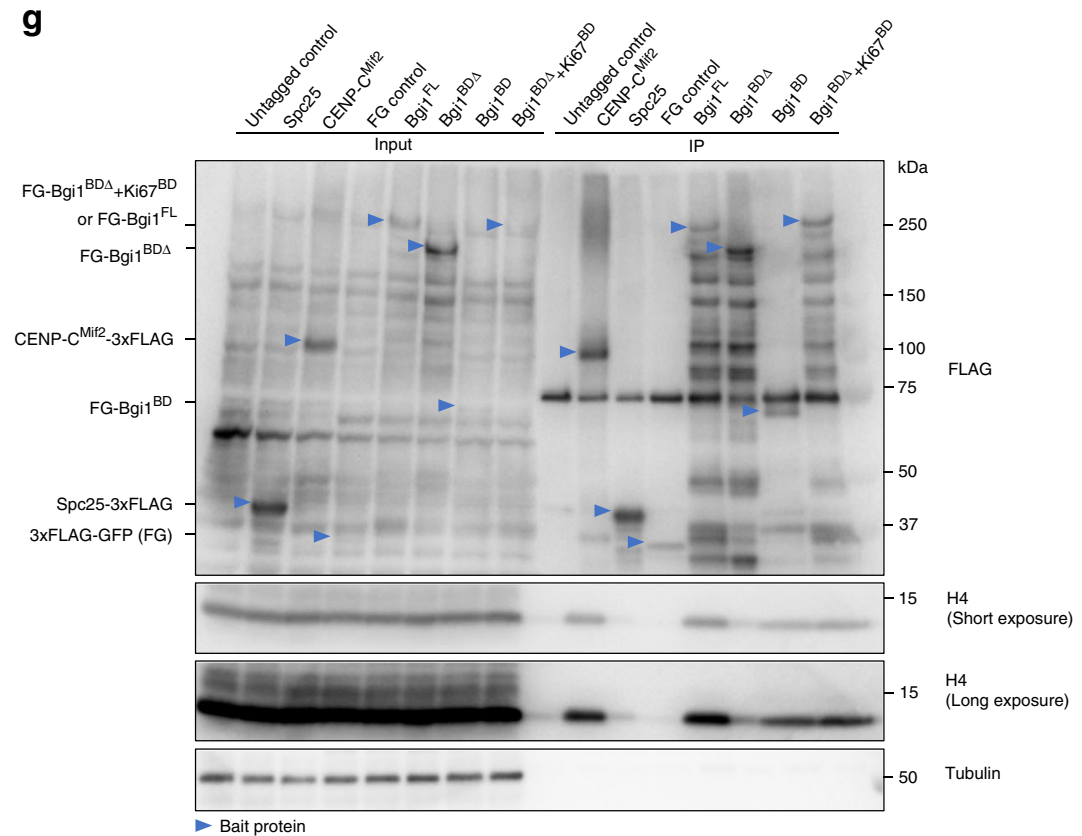

h

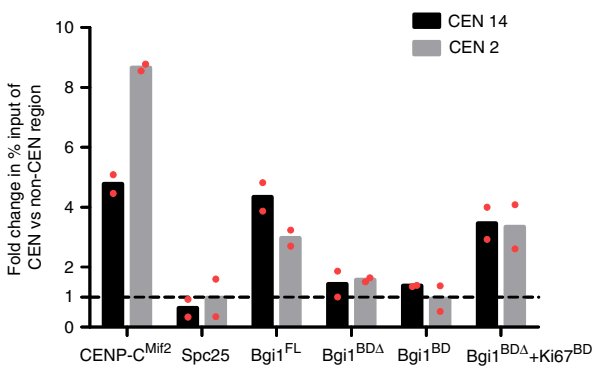

network, Mis $12^{\mathrm{Mtw} 1}$ and Nuf2 in metaphase, and Mis12 ${ }^{\mathrm{Mtw} 1}$ and $\mathrm{Knl1} \mathrm{Spc105}^{\mathrm{Si}}$ anaphase were reduced by a small but significant extent (Supplementary Fig. 7g-i).

In summary, we identified a kinetochore protein bridgin, which derives its ability to coordinate accurate chromosome segregation in a unique way by interacting with the outer kinetochore and centromeric chromatin. We propose that bridgin connects the outer kinetochore with centromeric chromatin following its recruitment to the outer kinetochore KMN network that also restricts bridgin's binding to centromeric chromatin.

\section{Discussion}

Our in silico analysis suggested that most inner kinetochore CCAN proteins were lost multiple independent times in the fungal phylum of Basidiomycota. To understand the unusual kinetochore composition that might have compensated for the loss of CCAN proteins, we analyzed the kinetochore interactome in the model basidiomycete, an important human fungal pathogen C. neoformans. In this study, we identified an outer kinetochore protein bridgin, along with all other evolutionarily conserved kinetochore proteins that are predicted to be present in 
Fig. 7 Interaction of bridgin with centromeric chromatin is established by the basic domain enriched with positively charged residues. a Schematic of the bridgin constructs wherein its basic domain was replaced with the basic DNA-binding domain from human Ki67. $\mathbf{b}$ Representative micrographs of $\mathrm{Bgi1}^{\mathrm{FL}}$ expressing SHR879, Bgi1 ${ }^{\mathrm{BD} \Delta}$ expressing SHR880, and the domain-swap chimera Bgi1 ${ }^{\mathrm{BD} \Delta}+\mathrm{Ki}^{\mathrm{B}} 7^{\mathrm{BD}}$ expressing SHR926 (SHR832::3 3 -FLAG-GFP$\left.B g i 1^{B D \Delta}+K i 67^{B D}\right)$. Scale bar, $3 \mu \mathrm{m}$. c Signal intensities of bridgin constructs mentioned in $\mathbf{b}$ were measured at metaphase and normalized to the mean intensity of $\mathrm{Bgi1}{ }^{\mathrm{FL}}$. The data represent the results of three independent experiments with 100 cells each. The red dot represents the mean of one experiment; mean \pm S.D. is shown. Kruskal-Wallis one-way analysis followed by Dunn's multiple comparison test was used to calculate the statistical significance of differences (the $p$ values show the difference compared to Bgif ${ }^{\mathrm{FL}}$ ). $\mathbf{d}$ The extent of complementation of bridgin constructs mentioned in c, wild-type control CNVY121, and the bridgin-null mutant SHR832 was measured. Indicated cell populations were measured $9 \mathrm{~h}$ post incubation at $37^{\circ} \mathrm{C}$. All values were normalized to wild-type control levels. Defects in nuclear segregation were measured as mentioned in Fig. $4 \mathrm{~b}$. The data represent the mean \pm S.D. of three independent experiments. One-way ANOVA test with Tukey's multiple comparison test was used to calculate the statistical significance of differences between the net missegregation and large-bud arrest population across strains. e Cells of varying numbers, $2 \times 10^{4}, 2 \times 10^{3}, 200,100$, and 50 , of Bgi ${ }^{\mathrm{BD} \Delta}$ expressing SHR880 and the domain-swap chimera Bgi ${ }^{\mathrm{BD} \Delta}+\mathrm{Ki} 67^{\mathrm{BD}}$ expressing SHR926 strains, were spotted on mentioned media plates. f Experimental design to determine Bgi1-BD interaction with chromatin in vivo by MNase IP. $\mathbf{g}$ FLAG immunoprecipitation of kinetochore proteins. $3 \times F L A G$ tagged proteins of Spc25 (SHR861,SPC25::SPC25-3×FLAG), CENP-CMif2 (SHR896), FLAG-GFP (FG) control (SHR918), Bgi1 FL (SHR879), Bgi1 ${ }^{\mathrm{BD} \Delta}$ (SHR880), $\mathrm{Bgi1}^{\mathrm{BD}}$ (SHR917), the domain-swap chimera Bgi1 ${ }^{\mathrm{BD}} \Delta_{+} \mathrm{Ki67} 7^{\mathrm{BD}}$ (SHR926), and untagged wild-type control (H99) were pulled down and levels of interacting histone $\mathrm{H} 4$ were determined. Bait proteins are marked by blue arrows. h Relative enrichment of FLAG-tagged proteins described in $\mathbf{g}$ at centromeres following the MNase IP. qPCR was performed using CEN2 and CEN14 and nonentromeric primer sets described in Fig. 2a followed by normalization to noncentromeric controls. The data represent the mean \pm S.D. of two independent experiments. Source data are available as a Source Data file.

C. neoformans. Our bioinformatic predictions and experiments converge on the fact that the CENP-C ${ }^{\text {Mif2 }}$ pathway is the single known linker pathway connecting centromeric chromatin to the outer kinetochore in C. neoformans, reminiscent of Drosophila melanogaster and Caenorhabditis elegans like kinetochores ${ }^{26,59-62}$. We demonstrate that bridgin through its FD and unstructured domain (USD) is recruited by the outer kinetochore and interacts with centromeric chromatin via its basic domain (BD) (Fig. 8a). Strikingly, unlike previously defined linker proteins CENP-C ${ }^{\text {Mif2 }} 38,39,63$, CENP-T ${ }^{\text {Cnn1 } 14,28,64}$, or CENP$\mathrm{U}^{\mathrm{Amel}} 39,40$, that require other inner kinetochore components for their recruitment ${ }^{1}$, bridgin is recruited by the outer kinetochore KMN network. Thus, the identification and characterization of bridgin in this study reveal an alternate pathway originating at the KMN network to connect the outer kinetochore with centromeric chromatin (Fig. 8a).

We describe that bridgin $\mathrm{BD}$ alone cannot specifically localize to centromeric chromatin. In addition, we demonstrate that BD's binding to centromeric chromatin is reliant on its positively charged residues rather than the primary amino acid sequence. Based on these results, we hypothesize that the binding of $\mathrm{BD}$ to centromeric chromatin is a consequence of specific kinetochore recruitment of bridgin through its FD and USD (Fig. 8a). Further, optimum levels of bridgin help restrict its kinetochore localization. It is noteworthy that the kinetochore localization of bridgin is dependent on multiple KMN network components, Knl1 Spc105 and Sos7 of the Knl1C, and the Mis12C-Ndc80C platform. Coincidentally, Bgi1 ${ }^{\mathrm{FD}}$ and Bgi1 $\mathrm{USD}$ independently exhibit kinetochore localization. These observations prompt us to speculate that each of the individual domains, FD and USD, may regulate interactions with a specific KMN component and their synergistic activity is important for maintaining cellular levels of bridgin at kinetochores. We are unable to determine the independent contribution of $\mathrm{Ndc} 80 \mathrm{C}$ and Mis12C, due to their interdependency, on bridgin recruitment. Reciprocally, the reduced levels of KMN components at the $\mathrm{M}$ phase in bgil $\Delta$ cells may be a consequence of bridgin's influence on the maintenance of the KMN components. These questions and findings necessitate further examination in the future.

Dsn1 autoinhibition ${ }^{34,35,37}$, which diminishes the Mis12C-CENP-C interaction, must be overcome by multiple kinetochore linker pathways. The essentiality of linker pathways to overcome Dsn1 autoinhibition is species-specific. While the Dsn1 autoinhibitory domain is absent in D. melanogaster 60,65 , that possesses a single kinetochore linker pathway CENP-C, $C$. neoformans retains the domain (Supplementary Fig. 8a). Although a recent study suggests Nnf1 to be the Dsn1 homolog in D. melanogaster, we were unable to identify the presence of the Dsn1 autoinhibitory domain in the suggested homolog ${ }^{26}$. Bridgin levels at the kinetochore reach the peak at anaphase, a stage of the cell cycle when Aurora B $\mathrm{B}^{\mathrm{Ipl} 1}$-mediated Dsn1 phosphorylation is suggested to be countered by the phosphatase activity of PP $1^{34,35}$ (Fig. 8a). The sharp reduction of Aurora $\mathrm{B}^{\mathrm{Ipl} 11}$ localization at anaphase kinetochores ${ }^{53}$ and the conservation of the amino terminus of CENP-C ${ }^{\text {Mif2 }}$ (Supplementary Fig. 8b) are observed in $C$. neoformans. Taken together, we propose that the kinetochore architecture alters during the metaphase-anaphase transition and that the bridgin pathway functions to reinforce/stabilize the outer kinetochore. It will be intriguing to test whether the presence of Dsn1 autoinhibition can provide a constraint driving evolution/ maintenance of multiple outer kinetochore linker pathways required for outer kinetochore reinforcement in organisms with monocentric chromosomes.

Outer kinetochore proteins are found to be more conserved than their inner kinetochore counterparts, including linker proteins across eukaryotes ${ }^{25,26}$. Thus, additional connections mediated by factors recruited by KMN proteins, like the bridgin pathway, may provide cells with an effective alternative toward outer kinetochore reinforcement. Bridgin homologs are identified across all subphyla in Basidiomycota (Fig. 8b). Strikingly, an inability to identify bridgin homologs in specific orders correlate with the presence of multiple known linker pathways (Fig. 8b). It would be worth investigating whether the presence of the bridgin pathway allowed more flexibility in the retention/loss of specific linker pathways in basidiomycetes. Genome sequencing of many basidiomycetes would help address the correlation. Further, it would be intriguing to recognize the contribution of the multiple linker pathways in organisms like Ustilago maydis, which retained CENP-T, CENP-C in addition to bridgin.

Bridgin homologs could be identified in the basal ascomycetous fungi of the class Pneumocystidales, such as Pneumocystis jirovecii (causative organism of pneumonia), and Taphrinales. Moreover, the existence of bridgin-like proteins outside fungi may suggest an ancient origin of this family of kinetochore proteins containing an FD (Supplementary Fig. 8c and Supplementary Data 4). Ki67, a component of the mitotic chromosome periphery ${ }^{57,66}$ but not reported to be associated with the kinetochore ${ }^{58}$, is the identified bridgin homolog in metazoa (Supplementary Fig. 8c). This raises interesting questions regarding the functional divergence and neofunctionalization of bridgin 


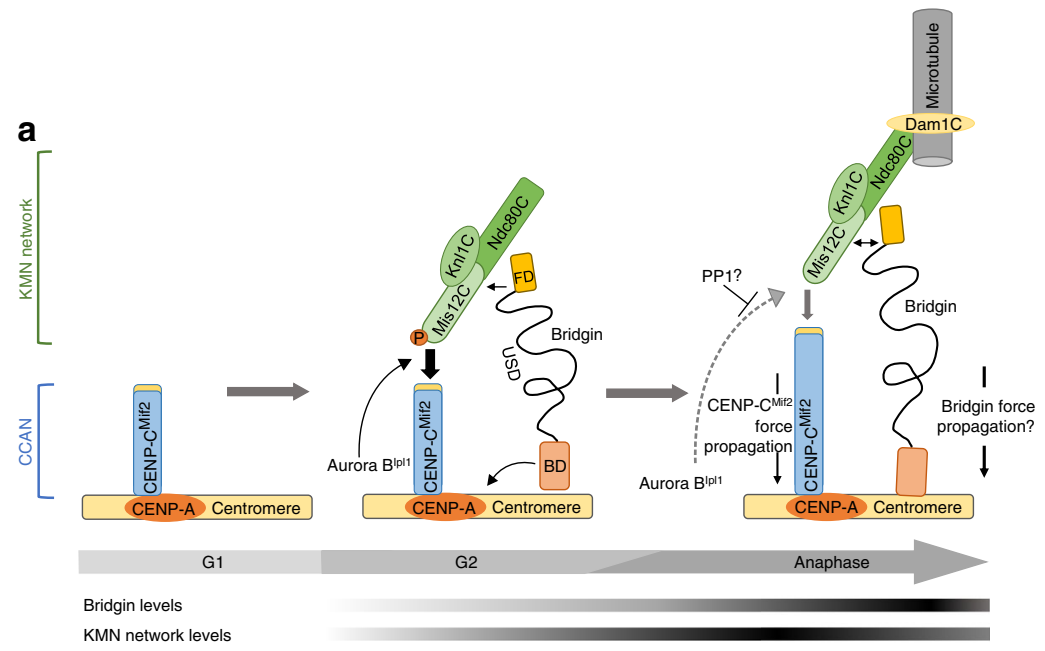

b

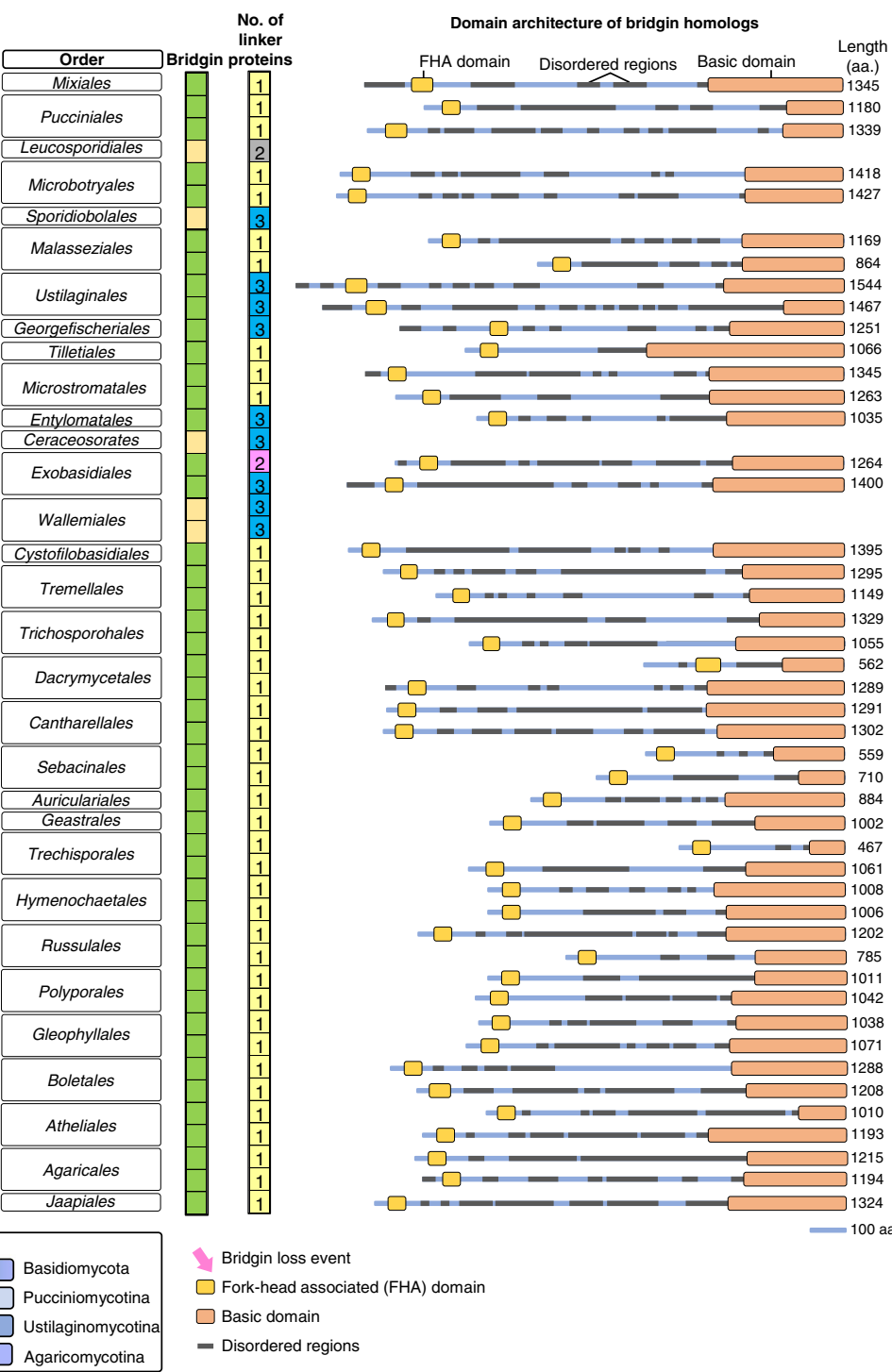

homologs invertebrates. Future experiments will reveal how bridgin is recruited onto kinetochore, how its chromatin binding is regulated, and to what extent bridgin can bear the load at the kinetochore.

There are limited experimental studies on kinetochores in nontraditional model eukaryotes ${ }^{25,67}$ and it, therefore, remains unclear whether there are lineage-specific kinetochore components because proteins such as bridgin cannot be identified by means of bioinformatics using known kinetochore proteins as a query. Thus, the identification of such kinetochore components emphasizes the significance of studying nonconventional systems. 
Fig. 8 Bridgin, a protein conserved across most basidiomycete species that lost one or more linker proteins, can bridge the outer kinetochore KMN network and centromeric chromatin. a A model describing bridgin as a kinetochore protein connecting the outer KMN network, through its FD and USD, and centromeric DNA directly via its BD. Restricted interaction of bridgin with centromeric chromatin in G2/M cells is a possible consequence of its outer kinetochore-specific recruitment. Increased bridgin localization is observed in anaphase. $\mathbf{b}$ Identification of bridgin homologs across Basidiomycota. Left, the presence (green box) or absence (yellow box) of a bridgin homolog is represented. The number of identified linker pathways has been mentioned and color-coded to represent the linker pathway(s) present. Bridgin loss events in basidiomycete lineages are represented by orange lines in the cladogram. Right, the domain architecture of identified bridgin homologs in Basidiomycota.

\begin{abstract}
Methods
Homolog detection. All searches were carried out in the NCBI nonredundant protein database and the UniProtKB database as available in July 2019. Searches for kinetochore homologs were initially carried out using iterative HMMER ${ }^{68}$ jackhammer searches $\left(E\right.$ value $\left.\leq 10^{-3}\right)$ with Pfam models for the mentioned kinetochore proteins. When available, models of both yeast and metazoan kinetochore homologs were considered. Obtained hits were validated by performing reciprocal HMMER searches. The secondary structure of obtained hits was validated using Jpred 4 and tertiary structure prediction using HHpred ${ }^{69}$ and/or Phyre $2^{70}$. Protein sequences that were unable to produce hits upon reciprocal searches or failed to conform to expected secondary and tertiary structures were discarded. Further searches were performed with the same criteria using identified homologs phylogenetically closest to the species in question. Species considered in the study are mentioned in Supplementary Data 1, when homologs were not identified from a specific strain, an obtained homolog from another strain of the same species was considered. Obtained hits when possible were validated with the identified homologs from C. neoformans. Known kinetochore homologs from S. cerevisiae, $S$. pombe, D. melanogaster, and $H$. sapiens were used to draw the matrix of kinetochore homologs.

Toward identifying homologs of bridgin, the conserved FD was taken as the bait for subsequent iterative HMMER jackhammer searches. Obtained hits were further screened for overall protein architecture (amino-terminus FD, an unstructured central region, and a basic carboxy-terminus (Fig. 8b and Supplementary Fig. 8c). The probability of protein disorder was predicted using IUPred $2 \mathrm{~A}^{71}$, and $\mathrm{pI}$ of the amino acid residues was predicted using ProtParam ${ }^{72}$. Using published multigene and genome-scale phylogenetic data from The Fungal Kingdom ${ }^{48}$, JGI MycoCosm ${ }^{73}$, Interactive Tree of Life (iTOL) $4^{74}$, and Wang et $\mathrm{al}^{75}$, the cladograms were drawn showing the relationship among the considered species.

Sos7 and bridgin alignments were generated using T-COFFEE v11.0 and visualized using JalView v2.11.1.0
\end{abstract}

Yeast strains and plasmids. A list of strains and plasmids used in the study can be found in Supplementary Table 2 and Supplementary Table 3, respectively. Primers used to generate the constructs are mentioned in Supplementary Table 4. Conditional kinetochore mutant strains were grown on $1 \%$ yeast extract, $2 \%$ peptone, and $2 \%$ galactose (YPG). All other strains were grown in $1 \%$ yeast extract, $2 \%$ peptone, and $2 \%$ dextrose (YPD) at $30{ }^{\circ} \mathrm{C}, 180 \mathrm{rpm}$, unless mentioned otherwise. Strains were maintained on YPD/YPG solidified with $2 \%$ agar and stored at $4{ }^{\circ} \mathrm{C}$ or $-80^{\circ} \mathrm{C}$ in $15 \%$ glycerol. Yeast strains are based on the haploid-type strain H99 or KN99 and generated by the standard procedure as previously described ${ }^{24}$ In brief, created native tagging and the GAL7 promoter $^{76}$ replacement cassettes were excised from the plasmid construct, appropriate restriction enzymes linearized $\mathrm{OE}$ cassettes, and deletion cassettes were generated by overlap polymerase chain reaction (PCR) and transformed into C. neoformans strains of appropriate background by biolistic transformation ${ }^{77}$. Transformed cells were selected on drug selection in YPG for the GAL7 promoter replacement strains to generate conditional mutants and YPD for all other strains.

Protein affinity purification and native ChIP. An overnight culture was inoculated at $0.1 \mathrm{OD}_{600}$ into fresh YPD, grown until $\sim 0.7 \mathrm{OD}_{600}$, and treated with $10 \mu \mathrm{g} /$ $\mathrm{ml}$ of TBZ for $3 \mathrm{~h}$. Cells were harvested, washed once in water followed by one wash with binding buffer BB150 (25 mM HEPES, pH 8.0, $2 \mathrm{mM} \mathrm{MgCl}_{2}, 0.1 \mathrm{mM}$ EDTA, $0.5 \mathrm{mM}$ EGTA, $0.1 \% \mathrm{NP}-40,150 \mathrm{mM} \mathrm{KCl}, 1 \times$ complete EDTA-free protease inhibitor (Roche), $1 \times$ PhosStop (Roche), and 15\% glycerol). Cells were resuspended in binding buffer $\left(100 \mathrm{OD}_{600} / \mathrm{ml}\right)$. Bead beating was used to lyse the cell suspension until $\sim 80 \%$ cell lysis was obtained. Lysates were centrifuged at $20,000 \mathrm{~g}$ for $20 \mathrm{~min}$, and the supernatant was collected. The extracted cell lysate was incubated with anti-FLAG M2 antibodies (Sigma) conjugated to Dynabeads ${ }^{\text {"x }} \mathrm{M}$ 280 sheep anti-mouse IgG (ThermoFisher Scientific) for $2 \mathrm{~h}$ at $4{ }^{\circ} \mathrm{C}$, under constant rotation. Unbound proteins were collected as flow-through, and proteins bound to antibody-conjugated beads were washed five times with BB150 w/o glycerol. Invert mixing was followed during each wash. Bound proteins were eluted in BB150 w/o glycerol $+200 \mu \mathrm{g} / \mathrm{ml}$ of $3 \times$ FLAG peptide (Sigma). Two elutes of $1 / 2$ volume each of the initial bead volumes was taken and pooled.

In all, $1 \mu \mathrm{g}$ of Anti-FLAG M2 antibody was conjugated to $10 \mu \mathrm{l}$ of Dynabeads M-280 sheep anti-mouse IgG (ThermoFisher Scientific) in $1 \times$ phosphate-buffered saline (PBS), $\mathrm{pH} 7.4$, and incubated for $1 \mathrm{~h}$ at room temperature (RT). It was washed twice with $1 \times$ PBS and resuspended in PBS. These anti-FLAG-conjugated beads were used for the lysate prepared from $100 \mathrm{OD}_{600}$ culture. Affinity purification samples that were processed subsequently for MS were started from a $2.25 \mathrm{~L}$ culture, yielding $\sim 4500 \mathrm{OD}_{600}$ cells. In all, $300 \mathrm{mM} \mathrm{KCl}$, where mentioned, was used throughout the affinity purification experiment as part of the binding buffer yielding BB300.

For GFP affinity purification, GFP-Trap agarose beads (ChromoTek) were used. Bound proteins were eluted by boiling the beads for $10 \mathrm{~min}$ in $1 \times$ sample loading buffer (50 mM Tris-HCl, pH 6.8, 2\% sodium dodecyl sulphate (SDS), $0.05 \%$ bromophenol blue, $10 \%$ glycerol, and 5\% 2-mercaptoethanol) and the supernatant was collected. Other steps of the affinity purification protocol were kept the same as mentioned above.

For MNase co-IP and native ChIP, lysates prepared after bead beating were subject to centrifugation at $3300 \mathrm{~g}$ for $10 \mathrm{~min}$. Following this, the supernatant was treated with MNase at RT to obtain digested chromatin ( $<2 \mathrm{~Kb}$ in length). Post digestion, the solution was centrifuged at 20,000 $\mathrm{g}$ for $20 \mathrm{~min}$. Subsequent steps followed were as described for the affinity purifications. For MNase native ChIP, DNA from the elute and input sample was extracted using GeneJET PCR purification kit (ThermoFisher Scientific). qPCR for input and IP was set up using centromere primers CN1 (CEN14)-5'-CCATCCAGTTCTTGCTTGAG-3' 5'-GCA AGGAATGTGTTGTCTGG- $3^{\prime}$ and CN3 (CEN2)-5'-CAGACCCTTCCTTCAG CCG-3' $5^{\prime}$-TGGCAAGGAGTCGTCAGCG-3' and noncentromeric primer set NC3 $5^{\prime}$-GATCAAGTATAGGCGAAGG-3' ${ }^{\prime}$-ATCTCTTATTCCCACTTCTACTC- ${ }^{\prime}$ located $\sim 825 \mathrm{~kb}$ away from the centromere on chromosome 1 . The reactions were supplemented with SYBR green (BioRad). Data were obtained using StepOne v2.3 (Applied Biosystems). Values were normalized to percent input observed in centromeric versus noncentromeric regions and plotted using GraphPad Prism.

Immunoblot analysis. For whole-cell lysates, $3 \mathrm{OD}_{600}$ cells were harvested and resuspended in $15 \%$ TCA overnight. About $500-\mu \mathrm{l} 0.5-\mathrm{mm}$ glass beads were added, and samples were vortexed for a total time of $15 \mathrm{~min}$, with intermittent cooling on ice. They were centrifuged at $15,000 \mathrm{~g}$ for $10 \mathrm{~min}$, and the obtained pellet was washed twice with $100 \%$ acetone, air-dried, and resuspended in $1 \times$ sample loading buffer and boiled for $10 \mathrm{~min}$. Samples were separated on a sodium dodecyl sulphate polyacrylamide gel electrophoresis (SDS-PAGE) and transferred to Immobilon-P (Merck).

For Supplementary Figs. 1c, 2d, e, and 6g, primary antibody and secondary antibody dilutions were made in skim milk. Proteins bound by antibodies were detected with Clarity western ECL (BioRad) and visualized with Versadoc (BioRad). For Fig. 7g and Supplementary Fig. 1a, 2b, 6a, b, d primary and secondary antibody dilution were prepared in Signal Enhancer Hikari (Nacalai tesque). ChemiDoc Touch (BioRad) was used to visualize proteins reacting with antibody in the presence of the substrate ECL Prime (GE Healthcare). Image ${ }^{78,79}$ and Image lab v6.0.0 (BioRad) was used to visualize and process images. Antibodies used are tabulated in Supplementary Table 5. Uncropped blots are presented in the Source Data File.

Mass spectrometry. Affinity-purified samples were separated on an SDS-PAGE followed by silver staining. Silver-stained gels were visualized using an Epson GTX980 scanner equipped with Epson Scan (Seiko Epson) v5.1.1.0. Isolated samples from the stained gel were Trypsin digested. Samples were subject to nano LC-MS-MS as described previously ${ }^{80}$. Briefly, after the gel slices were treated with DTT and iodoacetamide, in-gel digestion with $10 \mu \mathrm{g} / \mathrm{ml}$ modified trypsin (Sequencing grade, Promega) was performed at $37^{\circ} \mathrm{C}$ for $16 \mathrm{~h}$. The digested peptides were extracted with $1 \%$ trifluoroacetic acid and $50 \%$ acetonitrile, dried under a vacuum, and dissolved in $2 \%$ acetonitrile and $0.1 \%$ formic acid. The peptide mixtures were then fractionated by $\mathrm{C} 18$ reverse-phase chromatography $(3 \mu \mathrm{m}$, ID $0.075 \times 150 \mathrm{~mm}$, CERI, ADVANCE UHPLC, AMR Inc.) at a flow rate of 300 $\mathrm{nL} / \mathrm{min}$ with a linear gradient of $5-35 \%$ solvent $\mathrm{B}$ over $20 \mathrm{~min}$. The compositions of solvents $\mathrm{A}$ and $\mathrm{B}$ were $0.1 \%$ TFA in water and $100 \%$ acetonitrile, respectively. The data-dependent acquisition was performed by a hybrid linear ion trap mass spectrometer (LTQ Orbitrap Velos Pro, ThermoFisher Scientific) with Advanced Captive Spray SOURCE (AMR Inc.). The mass spectrometer was programmed to carry out 11 successive scans. The first scan was performed as a full-MS scan over the range $350-1800 \mathrm{~m} / z$ using Oubitrap analyzer at a resolution of 60,000 . The second-to- eleven scan events were detected by ion trap analyzer with automatic data-dependent MS/MS scans of the top 10 most abundant ion obtained in the first scan. MS/MS spectra were obtained by setting relative collision energy of $35 \%$ CID and exclusion time of $20 \mathrm{~s}$ for molecules of the same $\mathrm{m} / z$ value range. 
Using the MASCOT ver2.6.2 search engine in Proteome Discoverer 2.1.1.21 and 2.2.0.388 (ThermoFisher Scientific), the obtained spectra peaks were assigned using the UniProt proteome database for C. neoformans H99 database (ID: UP000010091 20171201downloaded (7340 sequences)). Fragment tolerance $0.80 \mathrm{Da}$ (Monoisotropic), parent tolerance 10 PPM (Monoisotropic), fixed modification of +57 on C

(Carbamidomethyl), variable modification of +16 on $\mathrm{M}$ (oxidation) and +42 on peptide amino terminus (Acetyl), and allowing for a maximum of 2 missed cleavages for CENP-CMif2, Dsn1, and Spc25 and 3 missed cleavages for bridgin samples. Scaffold (version Scaffold_4.10.0, Proteome Software Inc., Portland, OR) was used to validate MS/MS-based peptide and protein identifications. Peptide identifications were accepted if they exceeded specific database search engine thresholds. Protein identifications were accepted if they contained at least two identified peptides. Proteins that contained similar peptides and could not be differentiated based on MS/MS analysis alone were grouped to satisfy the principles of parsimony. Proteins sharing significant peptide evidence were grouped into clusters. Identified protein hits from CENP-C ${ }^{\text {Mif2 }}$, Dsn1, $\mathrm{Spc} 25$, and their untagged controls can be found in Supplementary Data 2 . To relatively quantitate protein abundance obtained within each of the experiments, Bgil ${ }^{\mathrm{FL}} 150 \mathrm{mM}$, Bgil $^{\mathrm{FL}} 300 \mathrm{mM}$, and $\mathrm{Bgil}^{\mathrm{BD} \Delta} 150 \mathrm{mM}$, emPAI ${ }^{81}$ (exponentially modified protein abundance index) values were determined using Scaffold 4.10.0 (Proteome Software). The higher the emPAI score, the more abundant the protein is in the mixture. Supplementary Data 3 summarizes the identified interacting protein hits from Bgil ${ }^{\mathrm{FL}}$, $\mathrm{Bgil}^{\mathrm{BD} \Delta}$, and their untagged control IPs.

Cross-linked ChIP and quantitative real-time PCR. ChIP assays were performed with some modification of previously described protocols ${ }^{82,83}$. In brief, $100 \mathrm{ml}$ of Bgil-GFP strain was grown until $\sim 1 \mathrm{OD}_{600}$. Cross-linking was performed for 20 min using formaldehyde to a final concentration of $1 \%$ and incubated at RT with intermittent mixing. The reaction was quenched by the addition of $2.5 \mathrm{M}$ glycine and further incubated for $5 \mathrm{~min}$. Fixed cells were harvested by centrifugation and resuspended in $9.5 \mathrm{ml}$ of deionized water, followed by the addition of $0.5 \mathrm{ml}$ of 2mercaptoethanol and incubated at $30^{\circ} \mathrm{C}$ for $60 \mathrm{~min}$ at $180 \mathrm{rpm}$. Cells were pelleted and resuspended in $10 \mathrm{ml}$ of spheroplasting buffer $(1 \mathrm{M}$ sorbitol, $0.1 \mathrm{M}$ sodium citrate, and $0.01 \mathrm{M}$ EDTA) containing $40 \mathrm{mg}$ of lysing enzyme from Trichoderma harzianum (Sigma). Spheroplasts were washed once with $15 \mathrm{ml}$ each of the following buffers: (1) $1 \times$ PBS, pH 7.4, (2) Buffer I (0.25\% Triton X-100, $10 \mathrm{mM}$ EDTA, $0.5 \mathrm{mM}$ EGTA, and $10 \mathrm{mM}$ Na-HEPES, pH 6.5), and (3) Buffer II (200 mM $\mathrm{NaCl}, 1 \mathrm{mM}$ EDTA, $0.5 \mathrm{mM}$ EGTA, and $10 \mathrm{mM}$ Na-HEPES, pH 6.5). Following which the spheroplasts were resuspended in $1 \mathrm{ml}$ of extraction buffer $(50 \mathrm{mM}$ HEPES, pH 7.4, $1 \%$ Triton X-100, $140 \mathrm{mM} \mathrm{NaCl}, 0.1 \%$ Na-Deoxycholate, and 1 mM EDTA) and sonicated to shear chromatin using a Bioruptor (Diagenode) for 30 cycles of 30-s on and 30-s off bursts at high-intensity setting. Sheared chromatin was isolated in the supernatant fraction after centrifugation for $15 \mathrm{~min}$ at $15,000 \mathrm{~g}$. Average chromatin fragment sizes ranged from 200 to $500 \mathrm{bp}$. In all, $100 \mu \mathrm{l}, 1 / 10$ th the volume, of the chromatin fraction, was kept for input DNA preparation, the remaining chromatin volume was divided into two halves of $450 \mu \mathrm{l}$ each for $(+)$ antibody and (-) antibody. For (+) antibody, $20 \mu \mathrm{l}$ of GFP-Trap agarose beads (ChromoTek) and $20 \mu \mathrm{l}$ of blocked agarose beads (ChromoTek) was added to (-). The tubes were incubated for $8 \mathrm{~h}$ to overnight on a rotator at $4{ }^{\circ} \mathrm{C}$. Following which the supernatant was isolated as flow-through, and the beads were washed twice with low-salt buffer, twice with the high-salt buffer, once with $\mathrm{LiCl}$ buffer, and twice with TE. Bound chromatin was eluted in two $250-\mu$ l elution using elution buffer. All three fractions $(\mathrm{SM},(+\mathrm{Ab})$, and $(-\mathrm{Ab}))$ were de-cross-linked (mixed with $20 \mu \mathrm{l}$ of $5 \mathrm{M} \mathrm{NaCl}$ and incubated at $65^{\circ} \mathrm{C}$ for $8 \mathrm{~h}$ to overnight), Proteinase $\mathrm{K}$ treated $(10 \mu \mathrm{l}$ of $0.5 \mathrm{M}$ EDTA, $20 \mu \mathrm{l}$ of $1 \mathrm{M}$ Tris- $\mathrm{HCl}, \mathrm{pH} 6.8,40 \mathrm{mg}$ of Proteinase $\mathrm{K}$ was added to the solution and incubated for up to $2 \mathrm{~h}$ at $45^{\circ} \mathrm{C}$ ). DNA was isolated using phenol:chloroform extraction followed by ethanol precipitation. Isolated DNA was air-dried and dissolved in $25 \mu$ of deionized water containing $25 \mu \mathrm{g} / \mathrm{ml}$ of RNase (Sigma).

All three samples (SM, (+), and (-) antibody) were subject to real-time quantitative PCR. The reaction mixture was set up using the iTaq ${ }^{\text {"m }}$ universal SYBR green Supermix (BioRad) with $1 \mu \mathrm{l}$ of the undiluted $(+\mathrm{Ab}),(-\mathrm{Ab})$ DNA samples, and SM (diluted 1:50). qPCR primers described above for the native ChIP were used. Data were obtained using CFX manager v3.1 (BioRad). Enrichment at centromeric regions was normalized to a control noncentromeric region. Values were plotted using GraphPad Prism. For ChIP-PCR assays, the obtained PCR products from SM, $(+)$, and $(-)$ antibody were separated on $2 \%$ agarose gels and visualized on BioRad Gel Doc XR using Quantity One v4.6.9.

Microscopy and analysis. Overnight cultures grown in YPD were subcultured into fresh YPD at $0.1 \mathrm{OD}_{600}$ and grown until $0.4-0.6 \mathrm{OD}_{600}$. Cells were isolated, washed twice in $1 \times$ PBS, and mounted on slides. Images for Supplementary Fig. $1 \mathrm{k}$ (CNAG_01340) were acquired using the Airyscan mode in the Zeiss LSM 880 confocal system equipped with an Airyscan module, $63 \times$ Plan Apochromat 1.4 NA. $\mathrm{Z}$ stacks were obtained at an interval of $166 \mathrm{~nm}, 488 / 516-$ and 561/595-nm excitation/emission wavelengths were used as GFP and mCherry, respectively. Airyscan images were processed using Zen Black v2.3 (Zeiss) and visualized in Image ${ }^{78,79}$. Images for Fig. 1d and Supplementary Fig. 1f, k were acquired in the Zeiss LSM 880 confocal system equipped with GaAsp photodetectors. $Z$ stacks were obtained at an interval of $300 \mathrm{~nm}, 488 \mathrm{~nm}$, and 561-nm excitation was used for GFP and
mCherry, respectively, and emission between $490-553 \mathrm{~nm}$ and $571-651 \mathrm{~nm}$ was captured. Images are represented as maximum-intensity projections.

Live-cell microscopy, images for kinetochore quantitation, and microscopybased assays were acquired using the Zeiss Axio Observer 7, equipped with Definite Focus.2, Colibri 7 (LED light source), TempController 2000-2 (PECON), 100× Plan Apochromat 1.4 NA objective, pco.edge 4.2 sCMOS, and Andor iXon Ultra 897 electron-multiplying charge-coupled device (CCD). Zen 2.3 (blue edition) was used for image acquisition and controlling all hardware components. Filter set 92 HE with excitation 455-483 and 583-600 nm for GFP and mCherry, respectively, and corresponding emission was captured at 501-547 and 617-758 nm. To limit the time taken for an image, a complete Z stack was obtained for each channel before switching.

For live-cell microscopy, an overnight culture grown in YPD was subcultured into fresh YPD at $\sim 0.1 \mathrm{OD}_{600}$ and grown for $2-3$ generations until $0.4-0.8 \mathrm{OD}_{600}$. Cells were harvested, washed in $1 \times$ PBS, and resuspended in synthetic complete media with 3\% dextrose. Cells were mounted onto an agarose pad (3\% dextrose, 3\% agarose in synthetic complete media) and sealed with petroleum jelly. Images were captured at time intervals of $0.5,1,2$, or $4 \mathrm{~min}$, as appropriate, with an EM gain of 300 and $\mathrm{Z}$ interval of $300 \mathrm{~nm}$. Z-stack projection of images is represented. For livecell quantitation of kinetochore signal, signal intensities were measured after the projection of $\mathrm{Z}$ stacks.

To study kinetochore interdependency, GAL7p conditional strains were grown overnight in YPG, subcultured at $0.2 \mathrm{OD}_{600}$, and grown until $0.8-1 \mathrm{OD}_{600}$. Cells were washed and resuspended in $1 \times$ PBS. Following which cells were inoculated into YPD (repressive, - ) and YPG (permissive, + ) at $0.1 \mathrm{OD}_{600}$. Timepoints chosen for the microscopic analysis of the repression phenotype were based on when the repressed kinetochore protein signals were no longer detectable at the kinetochore, which often coincided with an $\sim 90 \%$ loss in cell viability (Supplementary Fig. 2g). Images were acquired after 6, 12, 15, 18, 9, and $18 \mathrm{~h}$ for $\mathrm{CENP}_{-C^{\mathrm{Mif} 2}}$, Mis12 ${ }^{\mathrm{Mtw1}}$, Nuf2, Knl1 ${ }^{\mathrm{Spc105}}$, Dad1, and Dad2, respectively. Z stack was obtained at an interval of $300 \mathrm{~nm}$. Single $Z$ slice representing the maximum intensity of the tagged kinetochore proteins was represented. Quantitation of kinetochore signal was performed from large budded cells (budding index $\sim 0.55-0.90$ ).

To estimate the population of large buds and cells with segregation defects, cells were grown until early-log phase $0.8-1 \mathrm{OD}_{600}$ after subculture from an overnigh culture. They were imaged using the above-mentioned sCMOS camera with a Z interval of $300 \mathrm{~nm}$. Cells with a budding index of $>0.55$ were considered as large budded cells in mitosis. Chromatin marked with a GFP/mCherry-tagged histone $\mathrm{H} 4$ construct was used to observe missegregation events. In total, $>1000$ cells were measured for each independent experiment to estimate segregation defects. To calculate the percent large budded population after $10 \mu \mathrm{g} / \mathrm{ml}$ TBZ treatment, $>300$ cells were measured for each independent experiment.

Images for the $\mathrm{OE}$ assay of bridgin strains are representative maximum intensity projection images. KMN network and Dam1C components reach the peak intensity at metaphase, while bridgin exhibits maximum kinetochore intensity at anaphase. For quantitation of kinetochore signals, measurements were performed at the $\mathrm{M}$ phase to capture their signal at peak intensity, where possible. Components of the outer kinetochore are transiently localized to the kinetochore from G2 to M. Thus, clustered kinetochore signals in the daughter bud (budding index of $\sim 0.55-0.8$ ) provided us with a reliable stage to score for the kinetochore signal intensities. To maintain uniformity and ease of measurement, bridgin and inner kinetochore signal intensities were also measured at metaphase. Kinetochore signal measurement in interdependency assays and bgil $\Delta$ background were measured from the in-focus $Z$ plane exhibiting the most intense signal. Background signal measured from a region neighboring the kinetochore-measured signal in the same plane of the equal area was subtracted from the measured kinetochore intensity and normalized to the appropriate control and plot using GraphPad Prism v5.00 or v7.0a (GraphPad software). All acquired images were processed in Image ${ }^{78,79}$. For images wherein brightness and contrast are modified, the settings were applied uniformly across the entire image.

Budding index calculation. Budding index of a cell is defined as the ratio obtained by

(1) The diameter of the daughter cell/diameter of the mother cell

The diameter of the daughter and mother cell was measured along the mother-daughter axis using the line tool in Image ${ }^{79}$.

Generation of recombinant proteins. GST, GST-Bgil ${ }^{\mathrm{FD}}$ (residues 1-130), and GST-Bgil ${ }^{\text {BD }}$ (residues 1000-1295) were expressed from pGEX-6P-1 (GE Healthcare) in Rosetta2 (DE3) (Merck). GST and GST-Bgi1 ${ }^{\mathrm{BD}}$ were induced for expression using $1 \mathrm{mM}$ IPTG for $3 \mathrm{~h}$ at $37^{\circ} \mathrm{C}$. GST-FD was induced for expression overnight at $16^{\circ} \mathrm{C}$ using $0.2 \mathrm{mM}$ IPTG. Cells were harvested and lysed in lysis buffer (20 mM HEPES, pH 7.5, $300 \mathrm{mM} \mathrm{NaCl}, 1 \mathrm{mM}$ EDTA, $0.5 \mathrm{mM}$ TECP, and $1 \times$ complete EDTA-free protease inhibitor (Roche)) and $1 \times$ PBS with $1 \times$ complete EDTA-free protease inhibitor (Roche) for GST and GST-Bgil ${ }^{\mathrm{FD}}$. GST fusion proteins were affinity purified using Glutathione sepharose $4 \mathrm{~b}$ beads (GE Healthcare) and eluted using $20 \mathrm{mM}$ glutathione. GST-Bgil ${ }^{\mathrm{FD}}$ and GST-Bgil ${ }^{\mathrm{BD}}$ were further purified using anion exchange chromatography. The column was 
equilibrated using $20 \mathrm{mM}$ Tris- $\mathrm{HCl} \mathrm{pH} 7.5,1 \mathrm{mM}$ DTT. An elution gradient of $5-75 \% \mathrm{NaCl}$ was achieved using $20 \mathrm{mM}$ Tris- $\mathrm{HCl}, \mathrm{pH} 7.5,1 \mathrm{M} \mathrm{NaCl}$, and $1 \mathrm{mM}$ DTT. Relevant fractions were pooled, concentrated in Amicon-Ultra (Merck), frozen in liquid nitrogen, and stored at $-80^{\circ} \mathrm{C}$.

His-Bgi1 ${ }^{\mathrm{FL}}$ was expressed in SF9 cells. Cells were resuspended and lysed in binding buffer ( $20 \mathrm{mM}$ Tris- $\mathrm{HCl}, \mathrm{pH} 8.0,500 \mathrm{mM} \mathrm{NaCl}$, and $5 \mathrm{mM}$ imidazole). His-Bgil ${ }^{\mathrm{FL}}$ was affinity purified with Ni-NTA agarose (GE Healthcare), eluted with $20 \mathrm{mM}$ Tris- $\mathrm{HCl}, \mathrm{pH} 8,500 \mathrm{mM} \mathrm{NaCl}$, and $500 \mathrm{mM}$ imidazole. Purified protein was dialyzed against buffer containing Tris- $\mathrm{HCl}, \mathrm{pH} 7.5,1 \mathrm{mM}$ DTT, and $100 \mathrm{mM}$ $\mathrm{NaCl}$. Samples were concentrated using Amicon-Ultra (Merck), frozen in liquid nitrogen, and stored at $-80^{\circ} \mathrm{C}$. The absence of contaminating DNA was confirmed in all recombinant protein samples.

Viability assay. An overnight culture was inoculated into fresh YPD medium at $0.1 \mathrm{OD}_{600}$ and grown to $\sim 0.8 \mathrm{OD}_{600}$. The cell number was measured, followed by dilution of the cell suspension. Multiple dilutions containing 100-500 cells were subsequently plated on YPD solidified using $2 \%$ agar and grown for 2 days at $30^{\circ} \mathrm{C}$. The number of colonies formed was measured and plotted as normalized values to the wild-type control.

Serial dilution growth analysis. Cells were grown overnight, inoculated into fresh YPD at $0.2 \mathrm{OD}_{600}$, and grown until $0.8-1 \mathrm{OD}_{600}$. Following which cells were isolated and made up to $2 \mathrm{OD} / \mathrm{ml}$ in $1 \times$ PBS. Further dilutions were made as indicated in $1 \times$ PBS. In all, $2 \mu \mathrm{l}$ of the cell suspension was transferred onto appropriate agar plates as mentioned and incubated for 2 days for $30^{\circ} \mathrm{C}$, DMF control and $2 \mu \mathrm{g} / \mathrm{ml} \mathrm{TBZ}, 3$ days for $30^{\circ} \mathrm{C}+4 \mu \mathrm{g} / \mathrm{ml} \mathrm{TBZ}$, and $37^{\circ} \mathrm{C}$ and 7 days for $14^{\circ} \mathrm{C}$.

Electrophoretic mobility shift assays. Purified recombinant proteins of the mentioned molar ratio were incubated with 601 DNA $(2.5 \mathrm{pM})$ or $1 \mathrm{pM}$ of reconstituted nucleosomes in binding buffer $(20 \mathrm{mM}$ Tris, $\mathrm{pH} 7.5,100 \mathrm{mM} \mathrm{NaCl}$, $5 \%$ glycerol, and $1 \mathrm{mM}$ DTT). They were incubated for $1 \mathrm{~h}$ at $4{ }^{\circ} \mathrm{C}$ and separated on a PAGE gel, stained with GelRed, and visualized using a UVP gel documentation system equipped with Doc-It LS Image acquisition software (UVP) v6.7.1. Further, the gels were stained with Coomassie to visualize the protein complexes and imaged using a scanner.

To generate chicken or human nucleosomes, histone $\mathrm{H} 3.2$ and histone $\mathrm{H} 4$ tetramer or CENP-A and histone $\mathrm{H} 4$ tetramer were mixed with histone $\mathrm{H} 2 \mathrm{~A} / \mathrm{H} 2 \mathrm{~B}$ dimer with 601 DNA. $\mathrm{KCl}$ was added to the mixture to a final concentration of 2 $\mathrm{M}$. The subsequent mixture was dialyzed to a salt gradient buffer ( $2 \mathrm{M}$ to $200 \mathrm{mM}$ $\mathrm{KCl}, 10 \mathrm{mM}$ Tris- $\mathrm{HCl}, \mathrm{pH} 7.5,1 \mathrm{mM}$ EDTA, and $10 \mathrm{mM} \mathrm{DTT}$ ) overnight at $4^{\circ} \mathrm{C}$. The mixture was dialyzed to the final buffer $(100 \mathrm{mM} \mathrm{KCl}, 10 \mathrm{mM}$ Tris- $\mathrm{HCl}, \mathrm{pH}$ $7.5,1 \mathrm{mM}$ EDTA, and $10 \mathrm{mM}$ DTT) for $3 \mathrm{~h}$ at $4{ }^{\circ} \mathrm{C}$. The pellet in the mixture was removed by centrifugation at $5000 \mathrm{~g}$ at $4{ }^{\circ} \mathrm{C}$. To stabilize the resultant nucleosome, the supernatant was kept in the incubator at $37^{\circ} \mathrm{C}$ for $1 \mathrm{~h}$. The reconstituted nucleosomes were checked by native-PAGE and detected by EtBr staining for DNA.

Estimation of DNA methylation. Genomic DNA was isolated from overnight cultures of wild type and bgils, using a modified glass bead protocol ${ }^{76}$. In brief, cells were suspended in a microfuge tube containing $500 \mu$ of lysis buffer $(50 \mathrm{mM}$ Tris-HCl, pH 7.5, 20 mM EDTA, and 1\% SDS) and $250 \mu$ lof glass beads. Cells were disrupted by vortexing for $5 \mathrm{~min}$ and centrifuged for $1 \mathrm{~min}$ at $15,000 \mathrm{~g}$. To the supernatant, $275 \mu \mathrm{l}$ of $7 \mathrm{M}$ ammonium acetate was added and incubated at $65^{\circ} \mathrm{C}$ for $5 \mathrm{~min}$ and rapidly chilled on ice for $5 \mathrm{~min}$. In all, $500 \mu \mathrm{l}$ of chloroform was added, mixed, and centrifuged at $15,000 \mathrm{~g}$ for $3 \mathrm{~min}$. The supernatant containing DNA was precipitated with isopropanol, washed with $70 \%$ ethanol, dried, and resuspended in $50 \mu$ of deionized water.

The isolated genomic DNA was digested separately with CpG methylationsensitive (HhaI) or insensitive (HindIII) restriction enzymes (New England Biolabs) overnight with a no enzyme (uncut) control reaction. The digested DNA was diluted 1:50 and used for PCR amplification. Primer sets for PCR amplification of the centromeric region (5'-AGTCTCGTGTGGCTATGATT- $3^{\prime}$ and $5^{\prime}$-GGATCT GCTTGACAGTGTCA $-3^{\prime}$ ) and noncentromeric regions $\left(5^{\prime}\right.$-CCAACCGAAGCC CAAGACAA- $3^{\prime}$ and $5^{\prime}$-TTGAAGGATGATCCGGCCGA- $3^{\prime}$ ) were used. The obtained PCR products were subsequently separated by agarose gel electrophoresis using a $1 \%$ agarose gel and visualized by $\mathrm{EtBr}$ staining.

Statistics and reproducibility. Standard deviation and the mean of at least three independent experiments are mentioned in all plots unless mentioned otherwise. Statistical significance of differences was calculated as mentioned in the figure legends with one-way ANOVA with Dunnett's or Tukey's multiple comparison test, Mann-Whitney two-tailed, or Kruskal-Wallis one-way analysis followed by Dunn's multiple comparisons test. $P$ values $\geq 0.05$ were considered as nonsignificant (n.s.). Precise $p$ values are mentioned within figures if significant and above $p=0.0001$. All analyses were conducted using Microsoft Excel v2008 or GraphPad Prism version Windows v5.00 or v7.0a. Micrographs and immunoblotting images shown in figures are representative of at least two independent experiments with similar results.

Reporting summary. Further information on research design is available in the Nature Research Reporting Summary linked to this article.

\section{Data availability}

The source data underlying Fig. 1c, Figs. 2a, c-f, 3b, c, e, Fig. 4a, b, f, Fig. 5d, e, Fig. 6a, b, Fig. 7c, d, g, h, Supplementary Fig. 1a-c, h, Supplementary Fig. 2a, b, d, e, g, Supplementary Fig. 3a-j, Supplementary Fig. 4a, c, Supplementary Fig. 5c, e, f, Supplementary Fig. 6a-d, f, h, and Supplementary Fig. $7 \mathrm{c}-\mathrm{i}$ are provided in the Source Data file. All MS proteomics data that are presented in this study have been deposited to the ProteomeXchange Consortium via jPOST with the dataset identifiers "PXD021072" and "JPST000947", respectively. Publicly available databases used in the study include $C$. neoformans $\mathrm{H} 99$ proteome database (https://www.uniprot.org/proteomes/UP000010091) and Uniprot proteome database (https://www.uniprot.org/proteomes/).

Yeast strains and other data that support the findings of this study are available upon reasonable request from the corresponding authors. Source data are provided with this paper.

Received: 2 October 2019; Accepted: 10 November 2020; Published online: 08 January 2021

\section{References}

1. Musacchio, A. \& Desai, A. A molecular view of kinetochore assembly and function. Biology 6, 5 (2017).

2. McKinley, K. L. \& Cheeseman, I. M. The molecular basis for centromere identity and function. Nat. Rev. Mol. Cell Biol. 17, 16-29 (2015).

3. Fukagawa, T. \& Earnshaw, W. C. The centromere: chromatin foundation for the kinetochore machinery. Dev. Cell 30, 496-508 (2014).

4. Yadav, V., Sreekumar, L., Guin, K. \& Sanyal, K. Five pillars of centromeric chromatin in fungal pathogens. PLoS Pathog. 14, 1-7 (2018).

5. Suzuki, A. et al. How the kinetochore couples microtubule force and centromere stretch to move chromosomes. Nat. Cell Biol. 18, 382-392 (2016)

6. Joglekar, A. P. \& Kukreja, A. A. How kinetochore architecture shapes the mechanisms of its function. Curr. Biol. 27, R816-R824 (2017).

7. Lara-Gonzalez, P., Westhorpe, F. G. \& Taylor, S. S. The spindle assembly checkpoint. Curr. Biol. 22, R966-R980 (2012).

8. Caldas, G. V. \& DeLuca, J. G. Mad2 'opens' Cdc20 for BubR1 binding. Mol. Cell 51, 3-4 (2013).

9. Earnshaw, W. C. \& Rothfield, N. Identification of a family of human centromere proteins using autoimmune sera from patients with scleroderma. Chromosoma 91, 313-321 (1985).

10. Tachiwana, H. et al. Crystal structure of the human centromeric nucleosome containing CENP-A. Nature 476, 232-235 (2011).

11. Stoler, S., Keith, K. C., Curnick, K. E. \& Fitzgerald-Hayes, M. A mutation in CSE4, an essential gene encoding a novel chromatin-associated protein in yeast, causes chromosome nondisjunction and cell cycle arrest at mitosis. Genes Dev. 9, 573-586 (1995).

12. Perpelescu, M. \& Fukagawa, T. The ABCs of CENPs. Chromosoma 120, 425-446 (2011).

13. Foltz, D. R. et al. The human CENP-A centromeric nucleosome-associated complex. Nat. Cell Biol. 8, 458-469 (2006).

14. Hori, T. et al. CCAN makes multiple contacts with centromeric DNA to provide distinct pathways to the outer kinetochore. Cell 135, 1039-1052 (2008).

15. Okada, M. et al. The CENP-H-I complex is required for the efficient incorporation of newly synthesized CENP-A into centromeres. Nat. Cell Biol. 8, 446-457 (2006)

16. Yan, K. et al. Structure of the inner kinetochore CCAN complex assembled onto a centromeric nucleosome. Nature https://doi.org/10.1038/s41586-0191609-1 (2019)

17. Varma, D. \& Salmon, E. D. The KMN protein network-chief conductors of the kinetochore orchestra. J. Cell Sci. 125, 5927-5936 (2012).

18. Joglekar, A. P., Bloom, K. \& Salmon, E. D. In vivo protein architecture of the eukaryotic kinetochore with nanometer scale accuracy. Curr. Biol. 19, 694-699 (2009).

19. Westermann, S. et al. Formation of a dynamic kinetochore-microtubule interface through assembly of the Dam1 ring complex. Mol. Cell 17, 277-290 (2005).

20. Welburn, J. P. I. et al. The human kinetochore Skal complex facilitates microtubule depolymerization-coupled motility. Dev. Cell 16, 374-385 (2009). 
21. van Hooff, J. J. E., Snel, B. \& Kops, G. J. P. L. Unique phylogenetic distributions of the Ska and Daml complexes support functional analogy and suggest multiple parallel displacements of Ska by Dam1. Genome Biol. Evol. 9, 1295-1303 (2017).

22. Thakur, J. \& Sanyal, K. The essentiality of the fungus-specific Dam1 complex is correlated with a one-kinetochore-one-microtubule interaction present throughout the cell cycle, independent of the nature of a centromere. Eukaryot. Cell 10, 1295-1305 (2011).

23. Jenni, S. \& Harrison, S. C. Structure of the DASH/Daml complex shows its role at the yeast kinetochore-microtubule interface. Science 360, 552-558 (2018).

24. Kozubowski, L. et al. Ordered kinetochore assembly in the human-pathogenic basidiomycetous yeast Cryptococcus neoformans. MBio 4, 1-8 (2013).

25. D’Archivio, S. \& Wickstead, B. Trypanosome outer kinetochore proteins suggest conservation of chromosome segregation machinery across eukaryotes. J. Cell Biol 216, 379-391 (2017).

26. Hooff, J. J., Tromer, E., Wijk, L. M., Snel, B. \& Kops, G. J. Evolutionary dynamics of the kinetochore network in eukaryotes as revealed by comparative genomics. EMBO Rep 18, 1559-1571 (2017).

27. Drinnenberg, I. A., deYoung, D., Henikoff, S. \& Malik, H. S. Recurrent loss of $\mathrm{CenH} 3$ is associated with independent transitions to holocentricity in insects. Elife 3, 1-19 (2014).

28. Schleiffer, A. et al. CENP-T proteins are conserved centromere receptors of the Ndc80 complex. Nat. Cell Biol. 14, 604-613 (2012).

29. Navarro-Mendoza, M. I. et al. Early diverging fungus mucor circinelloides lacks centromeric histone CENP-A and displays a mosaic of point and regional centromeres. Curr. Biol. https://doi.org/10.1016/j.cub.2019.09.024 (2019).

30. Cheeseman, I. M., Chappie, J. S., Wilson-Kubalek, E. M. \& Desai, A. The conserved $\mathrm{KMN}$ network constitutes the core microtubule-binding site of the kinetochore. Cell 127, 983-997 (2006).

31. DeLuca, J. G. et al. Kinetochore microtubule dynamics and attachment stability are regulated by Hec1. Cell 127, 969-982 (2006)

32. Alushin, G. M. et al. The Ndc80 kinetochore complex forms oligomeric arrays along microtubules. Nature 467, 805-810 (2010).

33. Hara, M. \& Fukagawa, T. Where is the right path heading from the centromere to spindle microtubules? Cell Cycle 0, 1-13 (2019).

34. Lang, J., Barber, A. \& Biggins, S. An assay for de novo kinetochore assembly reveals a key role for the CENP-T pathway in budding yeast. Elife, 7, 1-27 (2018).

35. Hara, M., Ariyoshi, M., Okumura, E., Hori, T. \& Fukagawa, T. Multiple phosphorylations control recruitment of the KMN network onto kinetochores. Nat. Cell Biol. 20, 1378-1388 (2018).

36. Nishino, T. et al. CENP-T provides a structural platform for outer kinetochore assembly. EMBO J 32, 424-436 (2013).

37. Kim, S. \& Yu, H. Multiple assembly mechanisms anchor the KMN spindle checkpoint platform at human mitotic kinetochores. J. Cell Biol. 208, 181-196 (2015).

38. Milks, K. J., Moree, B. \& Straight, A. F. Dissection of CENP-C-directed centromere and kinetochore assembly. Mol. Biol. Cell 20, 4246-4255 (2009).

39. Dimitrova, Y. N., Jenni, S., Valverde, R., Khin, Y. \& Harrison, S. C. Structure of the MIND complex defines a regulatory focus for yeast kinetochore assembly. Cell 167, 1014-1027.e12 (2016).

40. Hornung, P. et al. A cooperative mechanism drives budding yeast kinetochore assembly downstream of CENP-A. J. Cell Biol. 206, 509-524 (2014).

41. Kato, $\mathrm{H}$. et al. A conserved mechanism for centromeric nucleosome recognition by centromere protein CENP-C. Science 340, 1110-1113 (2013).

42. Nishino, T. et al. CENP-T-W-S-X forms a unique centromeric chromatin structure with a histone-like fold. Cell 148, 487-501 (2012).

43. Huisin'T Veld, P. J. et al. Molecular basis of outer kinetochore assembly on CENP-T. Elife 5, 1-24 (2016).

44. Tromer, E. C., van Hooff, J. J. E., Kops, G. J. P. L. \& Snel, B. Mosaic origin of the eukaryotic kinetochore. Proc. Natl Acad. Sci. USA 116, 12873-12882 (2019).

45. Lin, X. \& Heitman, J. The biology of the Cryptococcus neoformans species complex. Annu. Rev. Microbiol. 60, 69-105 (2006).

46. Park, B. J. et al. Estimation of the current global burden of cryptococcal meningitis among persons living with HIV/AIDS. AIDS 23, 525-530 (2009).

47. Yadav, V. et al. RNAi is a critical determinant of centromere evolution in closely related fungi. Proc. Natl. Acad. Sci. USA 115, 3108-3113 (2018)

48. Heitman, J. et al. The Fungal Kingdom. (American Society of Microbiology, 2017). https://doi.org/10.1128/9781555819583.

49. Jakopec, V., Topolski, B. \& Fleig, U. Sos7, an essential component of the conserved Schizosaccharomyces pombe Ndc80-MIND-Spc7 complex, identifies a new family of fungal kinetochore proteins. Mol. Cell. Biol. 32, 3308-3320 (2012).

50. Li, N. et al. Structure of the eukaryotic MCM complex at 3.8 A. Nature 524, 186-191 (2015).
51. Shahnejat-Bushehri, S. \& Ehrenhofer-Murray, A. E. The ATAD2/ANCCA homolog Yta7 cooperates with Scm3 HJURP to deposit Cse4 CENP-A at the centromere in yeast. Proc. Natl. Acad. Sci. USA 117, 5386-5393 (2020).

52. Thakur, J. \& Sanyal, K. A coordinated interdependent protein circuitry stabilizes the kinetochore ensemble to protect CENP-A in the human pathogenic yeast Candida albicans. PLoS Genet. 8, e1002661 (2012).

53. Varshney, N. et al. Spatio-temporal regulation of nuclear division by Aurora B kinase Ipl1 in Cryptococcus neoformans. PLoS Genet. 15, e1007959 (2019).

54. Boehm, E. M., Gildenberg, M. S. \& Washington, M. T. The many roles of PCNA in eukaryotic DNA replication. Enzymes. 231-254. https://doi.org/ 10.1016/bs.enz.2016.03.003 (2016)

55. Dumesic, P. A. et al. Product binding enforces the genomic specificity of a yeast Polycomb repressive complex. Cell 160, 204-218 (2015).

56. MacCallum, D. E. \& Hall, P. A . The biochemical characterization of the DNA binding activity of pKi67. J. Pathol. 191, 286-298 (2000).

57. Cuylen, S. et al. Ki-67 acts as a biological surfactant to disperse mitotic chromosomes. Nature 535, 308-312 (2016).

58. Sobecki, M. et al. The cell proliferation antigen Ki-67 organises heterochromatin. Elife 5, 1-33 (2016).

59. Richter, M. M. et al. Network of protein interactions within the Drosophila inner kinetochore. Open Biol. 6, 150238 (2016).

60. Liu, Y. et al. Insights from the reconstitution of the divergent outer kinetochore of Drosophila melanogaster. Open Biol. 6, 150236 (2016).

61. Barth, T. K. et al. Identification of novel Drosophila centromere-associated proteins. Proteomics 14, 2167-2178 (2014).

62. Drinnenberg, I. A., Henikoff, S. \& Malik, H. S. Evolutionary turnover of kinetochore proteins: a ship of theseus? Trends Cell Biol. 26, 498-510 (2016)

63. Petrovic, A. et al. Structure of the MIS12 complex and molecular basis of its interaction with CENP-C at human kinetochores. Cell 167, 1028-1040.e15 (2016).

64. Bock, L. J. et al. Cnn1 inhibits the interactions between the KMN complexes of the yeast kinetochore. Nat. Cell Biol. 14, 614-624 (2012).

65. Venkei, Z. et al. Spatiotemporal dynamics of Spc105 regulates the assembly of the Drosophila kinetochore. Open Biol 2, 110032-110032 (2012).

66. Booth, D. G. \& Earnshaw, W. C. Ki-67 and the chromosome periphery compartment in mitosis. Trends Cell Biol. 27, 906-916 (2017)

67. Akiyoshi, B. \& Gull, K. Discovery of unconventional kinetochores in kinetoplastids. Cell 156, 1247-1258 (2014).

68. Potter, S. C. et al. HMMER web server: 2018 update. Nucleic Acids Res. 46, W200-W204 (2018).

69. Zimmermann, L. et al. A completely reimplemented MPI bioinformatics toolkit with a new HHpred server at its core. J. Mol. Biol. 430, 2237-2243 (2018).

70. Kelley, L. A., Mezulis, S., Yates, C. M., Wass, M. N. \& Sternberg, M. J. E. The Phyre2 web portal for protein modeling, prediction and analysis. Nat. Protoc. 10, 845-858 (2015).

71. Mészáros, B., Erdös, G. \& Dosztányi, Z. IUPred2A: context-dependent prediction of protein disorder as a function of redox state and protein binding Nucleic Acids Res. 46, W329-W337 (2018).

72. Gasteiger, E. et al. The Proteomics Protocols Handbook. The Proteomics Protocols Handbook Protein Identification and Analysis Tools on the ExPASy Server. (Humana Press, 2005). https://doi.org/10.1385/1592598900.

73. Grigoriev, I. V. et al. MycoCosm portal: gearing up for 1000 fungal genomes Nucleic Acids Res. 42, 699-704 (2014).

74. Letunic, I. \& Bork, P. Interactive Tree Of Life (iTOL) v4: recent updates and new developments. Nucleic Acids Res. 47, W256-W259 (2019).

75. Wang, Q. M. et al. Multigene phylogeny and taxonomic revision of yeasts and related fungi in the Ustilaginomycotina. Stud. Mycol. 81, 55-83 (2015).

76. Ruff, J. A., Lodge, J. K. \& Baker, L. G. Three galactose inducible promoters for use in C. neoformans var. grubii. Fungal Genet. Biol. 46, 9-16 (2009).

77. Davidson, R. C. et al. Gene disruption by biolistic transformation in serotype D strains of Cryptococcus neoformans. Fungal Genet. Biol. 29, 38-48 (2000)

78. del Valle, J., de la Oliva, N., Muller, M., Stieglitz, T. \& Navarro, X. Biocompatibility evaluation of parylene $\mathrm{C}$ and polyimide as substrates for peripheral nerve interfaces. in 2015 7th International IEEE/EMBS Conference on Neural Engineering (NER) 442-445 (IEEE, 2015). https://doi.org/10.1109/ NER.2015.7146654.

79. Abràmoff, M. D., Magalhães, P. J. \& Ram, S. J. Image processing with Image Part II. Biophotonics Int. 11, 36-43 (2005)

80. Oya, E. et al. H3K14 ubiquitylation promotes $\mathrm{H} 3 \mathrm{~K} 9$ methylation for heterochromatin assembly. EMBO Rep. e48111, 1-15 (2019).

81. Ishihama, Y. et al. Exponentially Modified Protein Abundance Index (emPAI) for estimation of absolute protein amount in proteomics by the number of sequenced peptides per protein. Mol. Cell. Proteomics 4, 1265-1272 (2005)

82. Sanyal, K. \& Baum, M. \& Carbon, J. Centromeric DNA sequences in the pathogenic yeast Candida albicans are all different and unique. Proc. Natl. Acad. Sci. USA 101, 11374-11379 (2004).

83. Dubin, M., Fuchs, J., Gräf, R., Schubert, I. \& Nellen, W. Dynamics of a novel centromeric histone variant $\mathrm{CenH} 3$ reveals the evolutionary ancestral timing of centromere biogenesis. Nucleic Acids Res. 38, 7526-7537 (2010). 


\section{Acknowledgements}

The authors thank the members of the Sanyal and Fukagawa laboratories for their inputs and discussions. We thank Daniel Gerlich (Institute of Molecular Biotechnology, Vienna, Austria) for generously providing us the Ki67 plasmids. The authors are grateful to Masatoshi Hara, Mariko Ariyoshi, Reito Watanabe, and Fumiaki Makino from the Fukagawa laboratory for their technical assistance. We also thank Akira Shinohara and his group members for allowing us to use their facilities. We acknowledge B. Suma at the confocal imaging facility, JNCASR, for assistance in imaging. A joint grant from the Department of Science and Technology (DST), India, and Japan Society for the Propagation of Science (JSPS), Japan aided in the travel of S.S. between the Sanyal and Fukagawa laboratories (DST/ INT/JSPS/P-240/2017). Research in the Sanyal lab was funded by the grants from DST, Govt. of India (GOI) to KS (CRG/2019/005549), Department of Biotechnology (DBT), GOI at JNCASR (BT/INF/22/SP/27679/2018), JC Bose National Fellowship from Science and Educational Research Board, GOI, (JCB/2020/000021), and intramural funding from JNCASR to KS. KS was a Tata Innovation Fellow DBT, GOI (BT/HRD/35/01/03/2017). S.S. thanks Council for Scientific and Industrial Research (09/733(0192)/2014-EMR-I) and JNCASR for his fellowship. Research in the Fukagawa laboratory was supported by JSPS KAKENHI Grant nos. 17H06167, 16H06279, and 15H05972 and Osaka University International Joint Research Promotion Program type A.

\section{Author contributions}

S.S. and K.S. conceived the project. S.S., K.S., T.H., and T.F. designed the experiments. R. $\mathrm{N}$. performed the mass spectrometry and S.S. performed the rest of the experiments. T.H. assisted with affinity purification for mass spectrometry. S.S. and K.S. wrote the paper. S.S., K.S., T.F., and T.H. revised the paper. All authors approved the final version. K.S. gathered funding and supervised the entire project.

\section{Competing interests}

The authors declare no competing interests.

\section{Additional information}

Supplementary information is available for this paper at https://doi.org/10.1038/s41467020-20161-9.

Correspondence and requests for materials should be addressed to T.F. or K.S.

Peer review information Nature Communications thanks Bungo Akiyoshi, Geert Kops, Kozo Tanaka and the other, anonymous, reviewer(s) for their contribution to the peer review of this work. Peer reviewer reports are available.

Reprints and permission information is available at http://www.nature.com/reprints

Publisher's note Springer Nature remains neutral with regard to jurisdictional claims in published maps and institutional affiliations.

\section{(c) (i)}

Open Access This article is licensed under a Creative Commons Attribution 4.0 International License, which permits use, sharing, adaptation, distribution and reproduction in any medium or format, as long as you give appropriate credit to the original author(s) and the source, provide a link to the Creative Commons license, and indicate if changes were made. The images or other third party material in this article are included in the article's Creative Commons license, unless indicated otherwise in a credit line to the material. If material is not included in the article's Creative Commons license and your intended use is not permitted by statutory regulation or exceeds the permitted use, you will need to obtain permission directly from the copyright holder. To view a copy of this license, visit http://creativecommons.org/ licenses/by/4.0/.

(c) The Author(s) 2021 